\title{
التشبيه في الفكر الأسطوري عند العراقي القديم
}

\section{د. فايز أنور عبدالمالبـ}

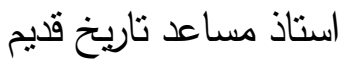

كلية الآداب - جامعة دمنهور

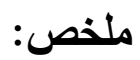

احتوى الفكر الأسطوري في العراق القديم على صيغة النتبيه، والتي قصد الكاتب

من ورائها تأكيد صفات ومعانى لآلهة العراق القنيم، فتم التنتييه بالسماء والأرض، والنيف والنتبيه

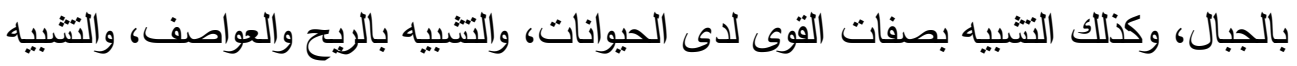

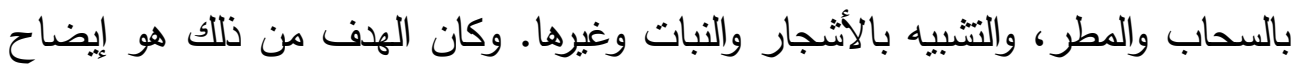

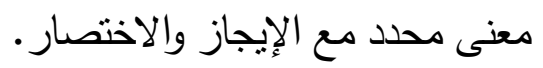

Likenning in the Mythological Thought for the Ancient Iraqi

\section{Summary}

The mythical the likening which the author intended to emphasize traits and meanings of Ancient Iraqi Gods. There was likening to heaven and earth, to mountains, and to Animal powers, to winds and tornadoes, to clouds and rain, to tree and plants... etc. the aim of such similes was to clarify a specific meaning briefly.

التشبيه في اللغة: هو التثنيل، ويقال أثنبه فلانًا وشابهه، وتشبه فلان بكذا.' أما

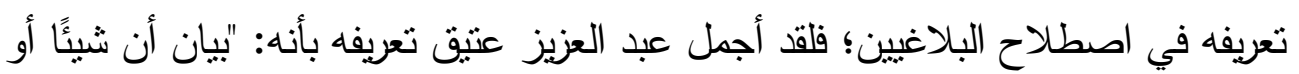

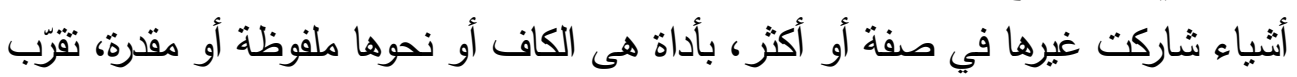

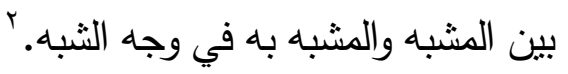
وسيتم تتاول التتبيه في الفكر الأسطوري للعراق القديم، على النحو التالي:

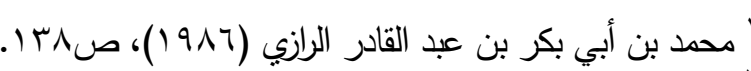

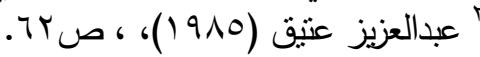


ولقد تتاولت الأساطير العراقية القديمة خلق الكون، وكان الإله "أنو "' أهم الآلهة في

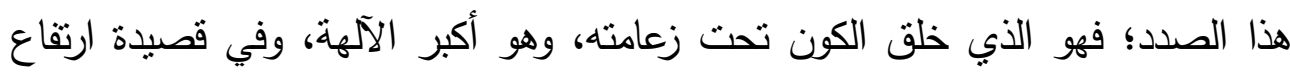

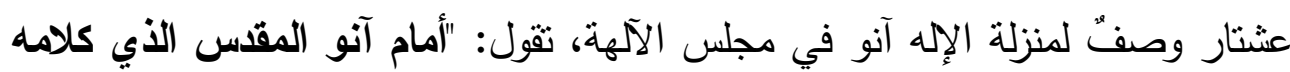
غير متناه، الآلهة العظام برضا قوى ينحنون أمامه كسيف المنجل".

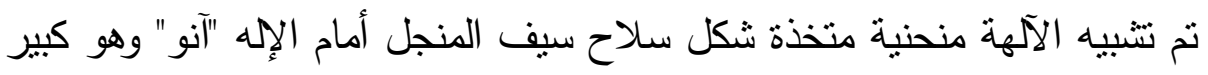

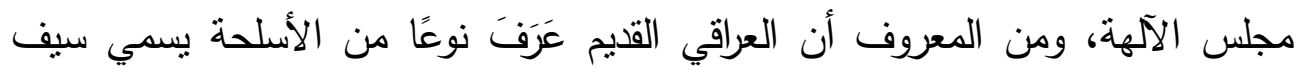

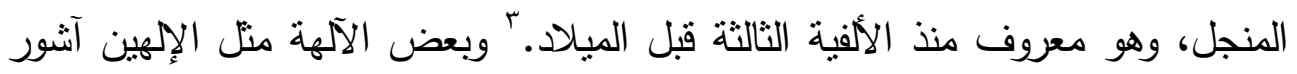
ونينورتا گ كان يحمل كل منهما سيف المنجل.

ومعنى ما سبق أن هذا السلاح كان معروفًا لدى العراقي القيم فجاء هناء هنا النتبيه

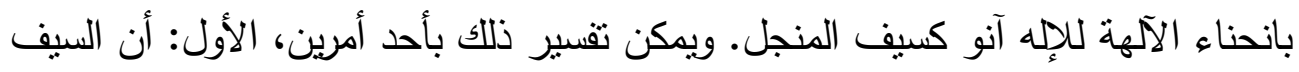

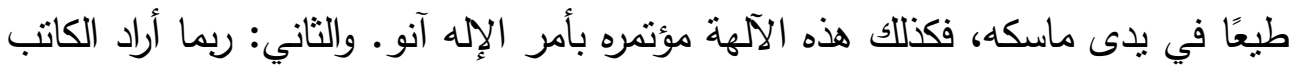
استلهام هيئة الانحناء من السيف؛ فإن الآلهة منحنية أمام الإله آنو.

الإله إنليل: - ne

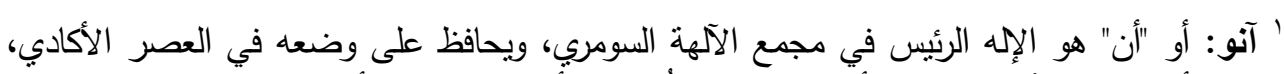

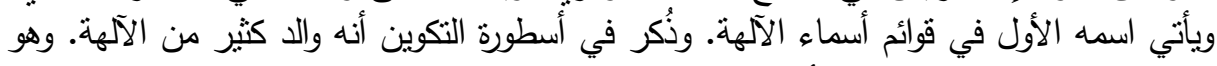

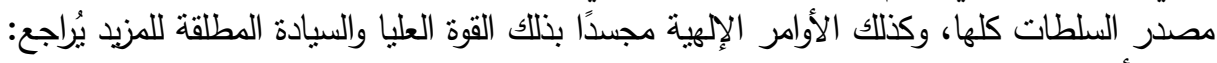

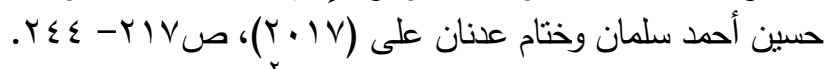

$$
\begin{aligned}
& \text { Black. J and Green. A (2004), p.19. }
\end{aligned}
$$

" نينورتا: آلهة سومرى يعنى (سيد الأرض) وعرف في الديانة الأكادية بنفس الاسم، وهو ابن الإله إينليل

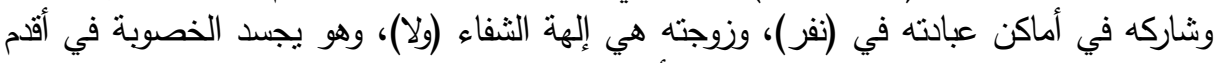

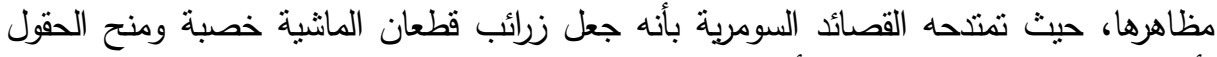

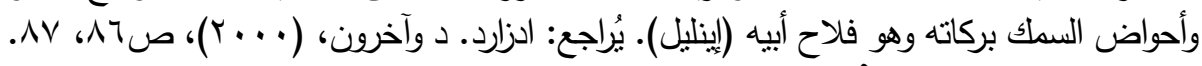

Tallay. O (2005), p.82. 
وقيل عن الإله إنليل (ايلليل)، أن: "تواميسه المقسة كنواميس خفية ما من أحد

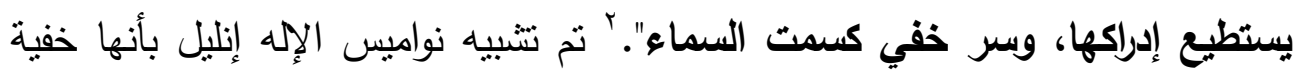

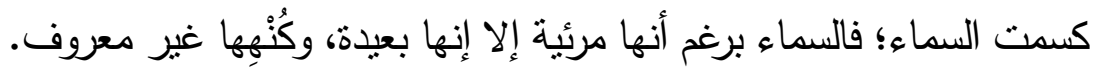

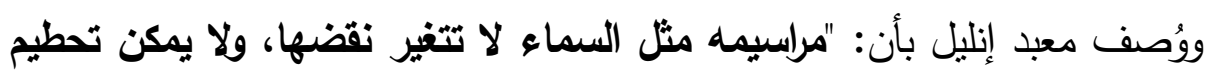

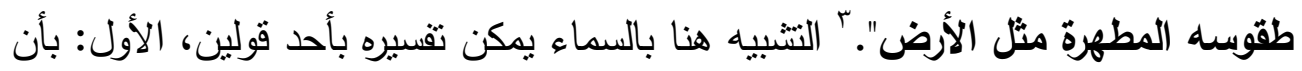

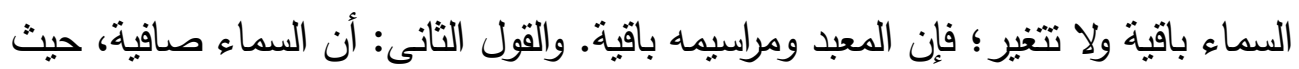

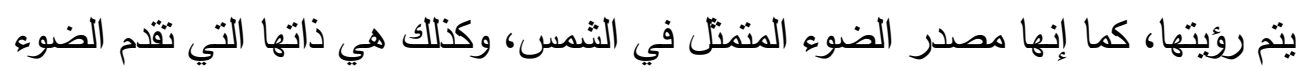

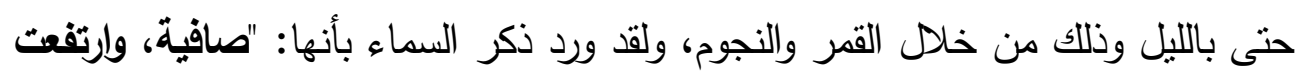

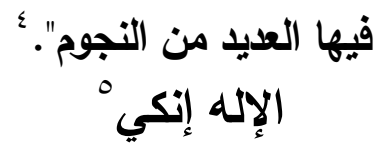

عهد الإله "أنو" للإله إنكي إصلاح الرى والزراعة إليه، فأني: أن إنكي هو المسؤول

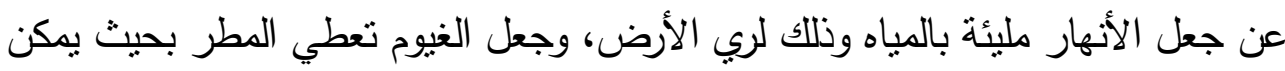

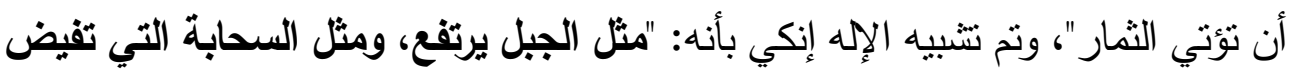

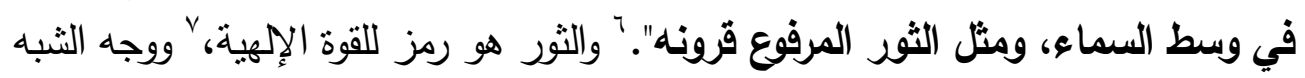

' إنليل: عرف كإله رئيس في مجمع الآلهة السومرن وكان يظهر في البداية إلى جانب والده (آن) ثم ما

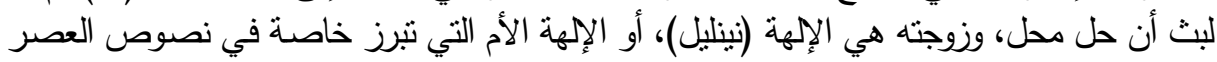

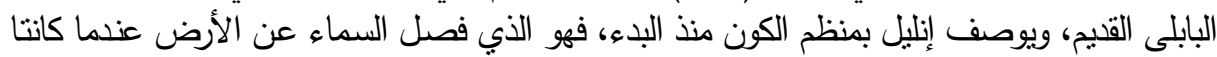

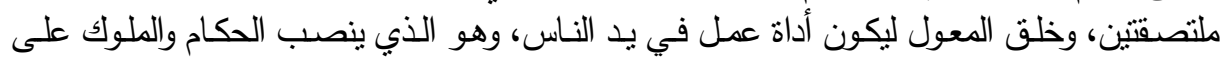

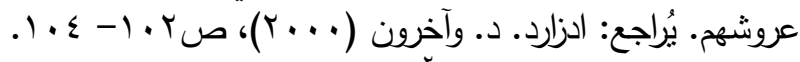
r Jacobsen, T (2010), p.15.

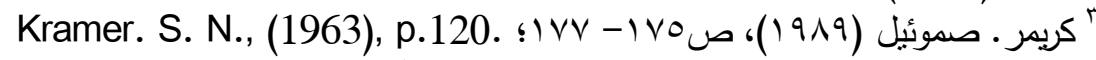

Konstantopoulos. G. V (2015) pp.86-87.

إنكى: يعني في السومرية سيد الأرض أو سيد الأسفل، ويقابله في الأكادية اسم (إيا)، ويعرف أنه إله الإنه

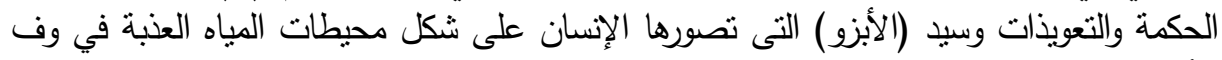

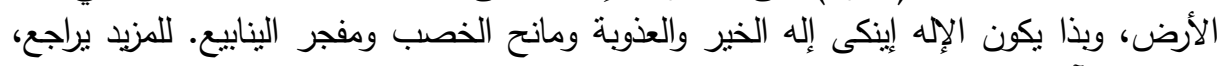

Espak. P (2010), pp. 49, 108.

Taheri. A (2013), p.19. 


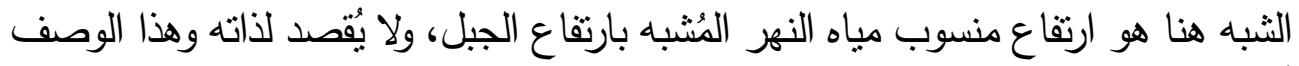

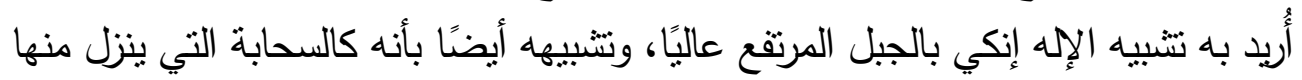

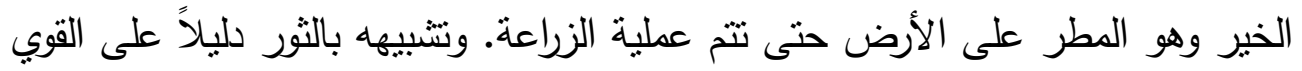

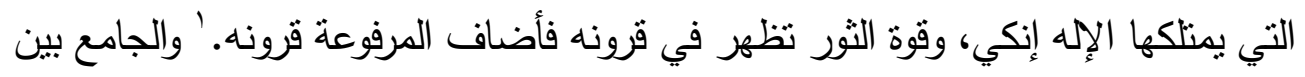

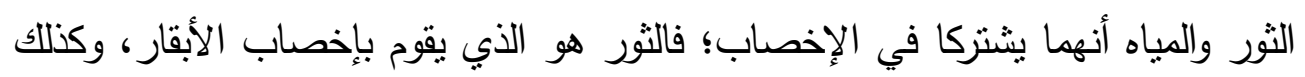

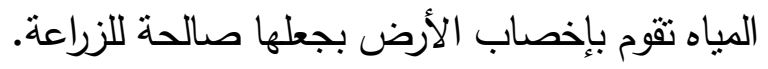

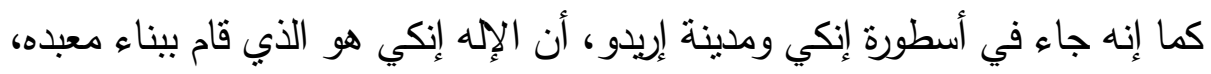

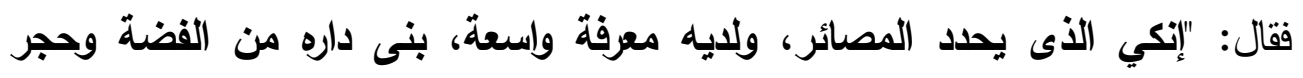

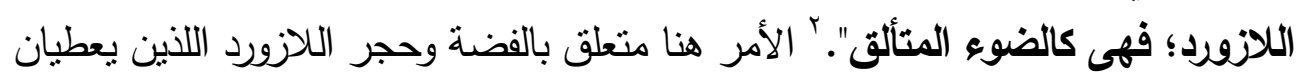

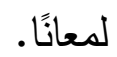

كما جاء في أوصاف الإله إنكي أنه: "لحيته مثل اللازورد"، " ووصف إنكي بانه:

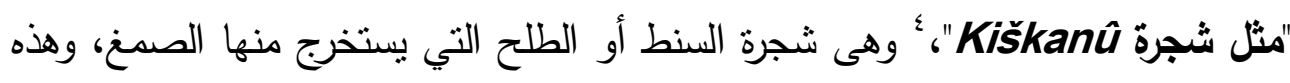

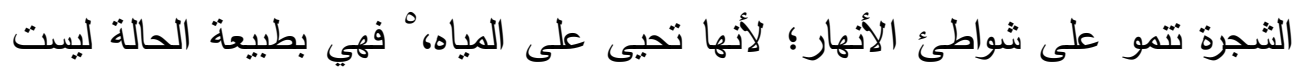

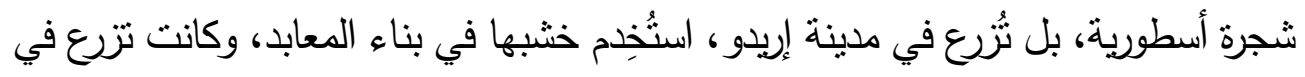

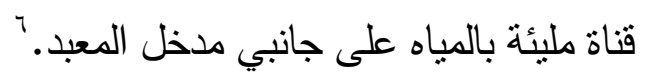

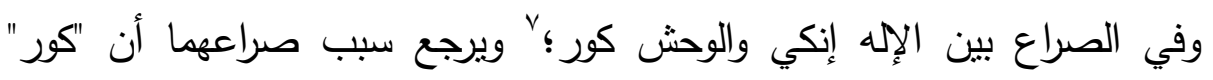

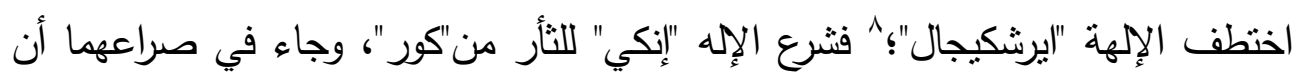

' Tallay. O (2013), p.41.

'Espak. P (2010), p.78.

'Espak. P (2007), p.44.

'Black. J and others (2000), p.46.

- Thompson. R. C (1948), p.288.

"Espak.P (2007), p. 54.

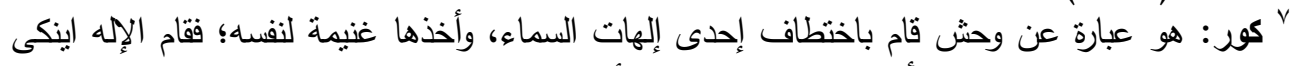

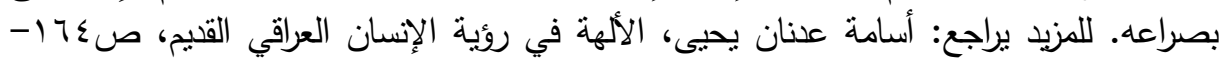

^ إيرثكيجال: هي الإلهة الملكة الأعظم، وهي التى تحكم العالم السفلى. يراجع: 
"كور": "ثن الحرب عليها - على سفينة إنكي - كالزويعة، وأحاط بها من كل جهة".

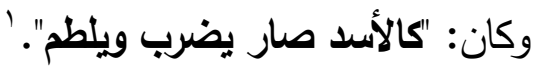

ظَهَرَ "كور" في هذا الصراع كالزوبعة، ومن المعروف أن الزوبعة والإعصار يؤثنثان

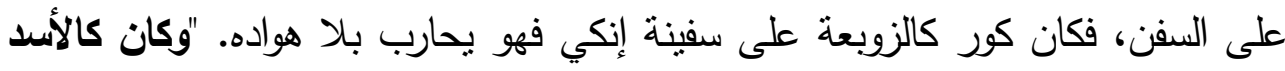

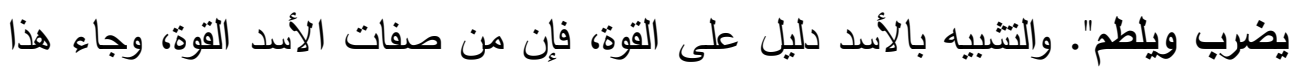

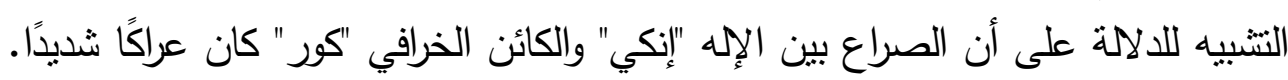

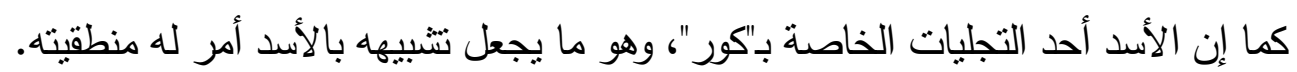

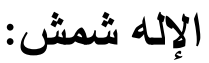

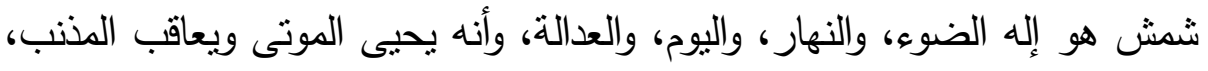

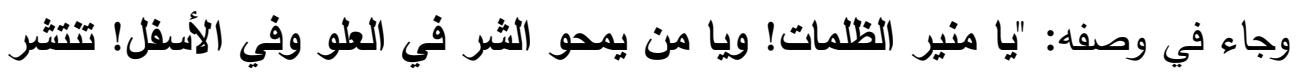

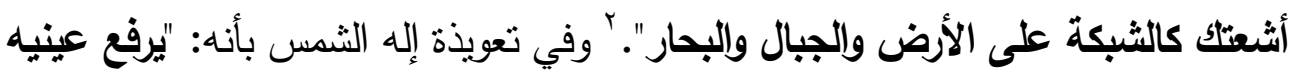

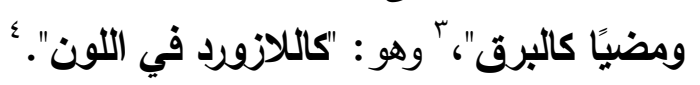

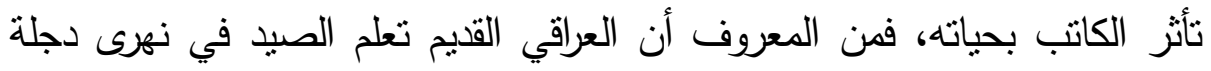

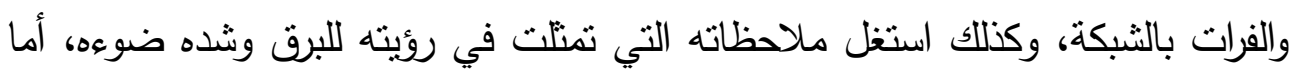

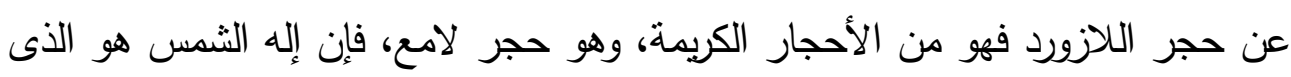
يجعل الثمس نتشر أنثعتها لنشيِير الكون. الإله نرجال:

وجاء عن الإله نرجالْ إله العالم الأسفل ورب الأرض، أنه: "يهب كالريح، وأنه ثقيل مثل العاصفة"، وبعد أن أرعب نرجال الددن، قيل عنه: "قمت بوضع قدمك عليهم مثل ثون الأن

Black. J and Green. A (2004), p.77.

'Schwemer. M (2008), p.138.

'Stephens. F. J (1969), p.387.

rPolonsky. J (2002), p.191.

'Polonsky. J (2002), p.192.

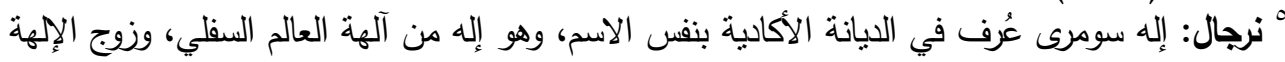
(إريشكيجال)، وهو يجسد وظائف في الأصل كإله في العالم السفلى إلا إنها ليست وظيفته الوحيدة، 
البرية، وقتت بضنط قرنك الكبير عليهم"، وجاء عنه أنه: "سكب دمهم مثل المطر في

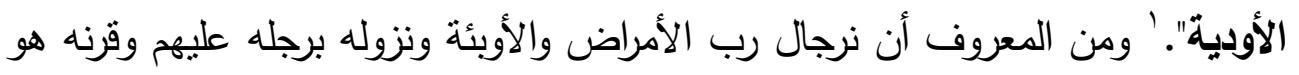

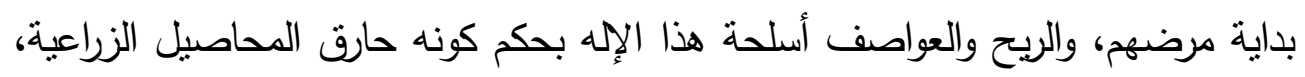
وهو أمر لازم له رياح عانية نؤدي إلى حريق تام مُدمر .

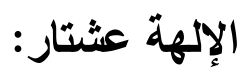

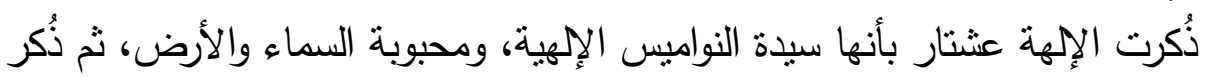

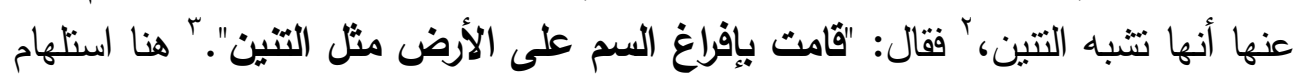

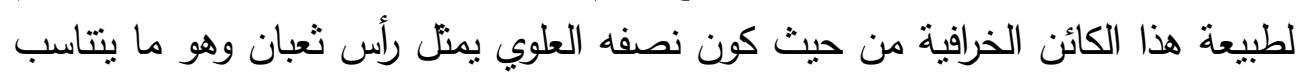

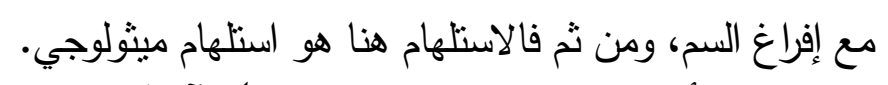
وذكر أيضًا: "يا سياتي إن الانوناكي" الآلهة العظام، ينهزمون أمامك إلى الكى الكهوف

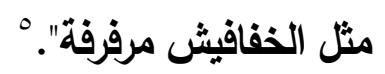

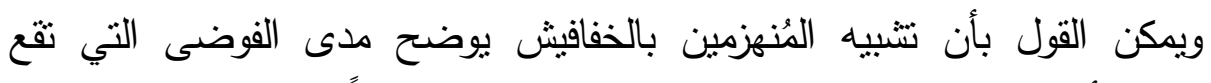

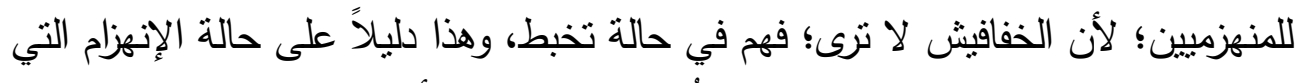

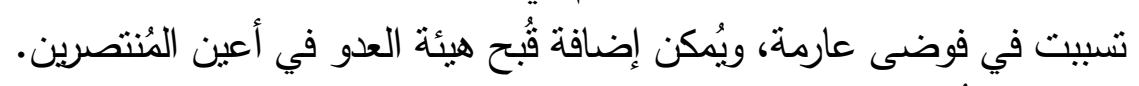

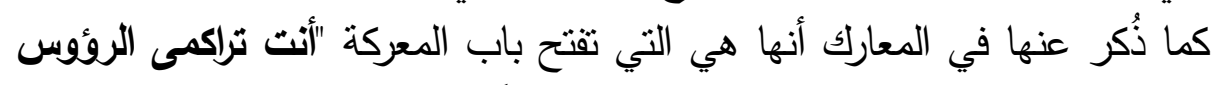

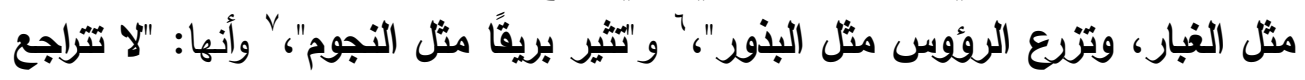

=فهو يجسد وظائف إله علوي أيضًا، وتتسب إليه قسوة حرارة الثمس المحروقة، وهو الذبي يسبب

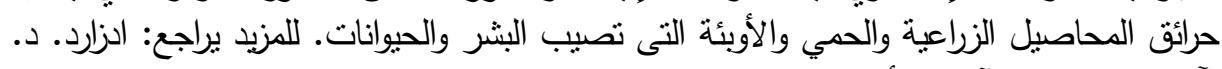

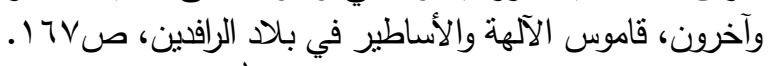

' Kramer. S. N (1989), pp.308-309.

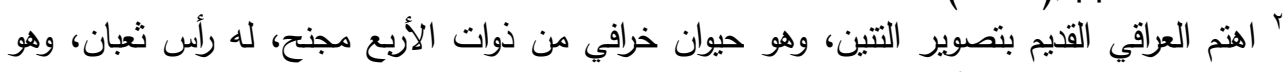

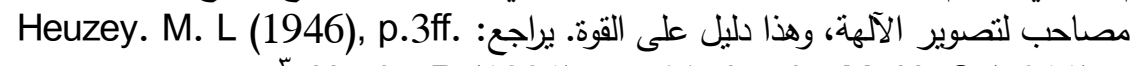
r Harris. R (1991), p.265; Lewis. M. H. C (2011), p.62. ؛ الأنوناكى: آلهة في السماء هبطت إلى الأرض، ومرنبط ذكرها بآلهة الإيجيجي. يُراجع: Jordan. M. (2004), p.23.

- Kotzé. Z (2017), p.114.

$\checkmark$ Harris. R (1991), p.269.

${ }^{v}$ Smith. M. S (2014) p.49. 
في المعركة مثل شاب هى شجاعة وماهرة في المعركة"، وأنها: "فى الحرب مثل

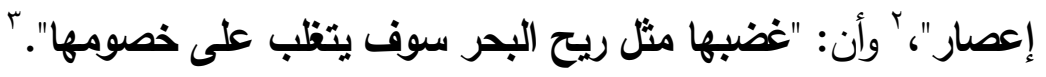

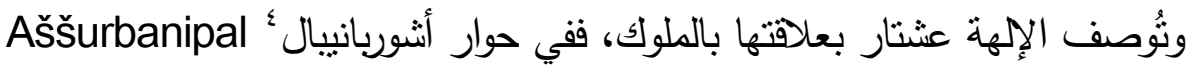

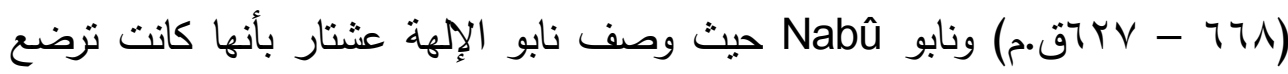

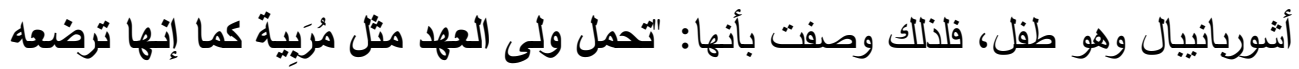

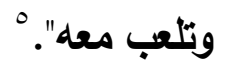

وفي نص نزول الإلهة عشتار إلى عالم الأموات، وأنها ستخخل إلى عالم محرم فيه

النور ، ملئ بالغبار، وأكلهم هناك الطين، جاء: "لإبسين كالطيور كسوة الجناح".

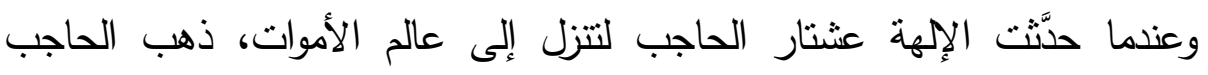

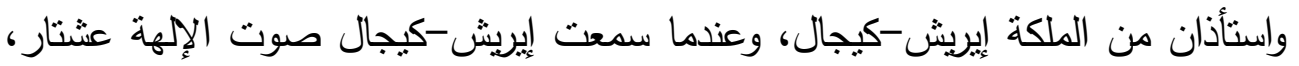

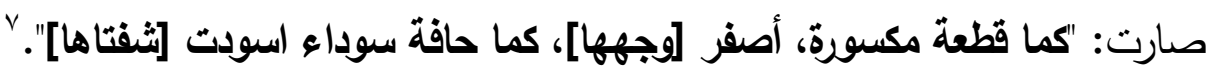

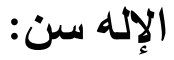

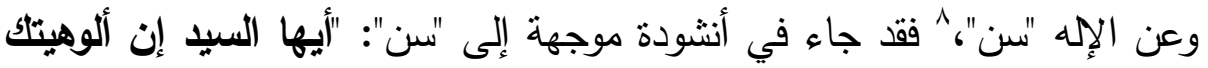

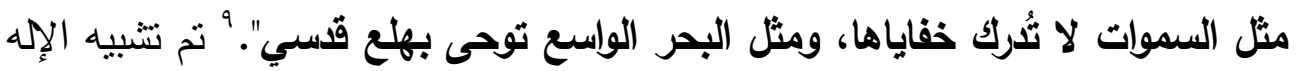

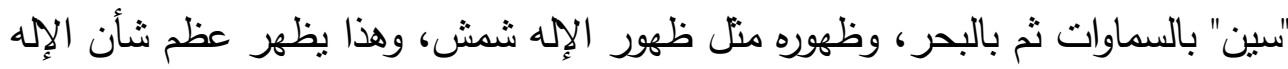

$\begin{array}{ll} & \text { Lewis. M. H. C (2011), p.50. } \\ \text { Lewis. M. H. C (2011), p.58. } \\ \text { Lewis. M. H. C (2011), p.50. }\end{array}$

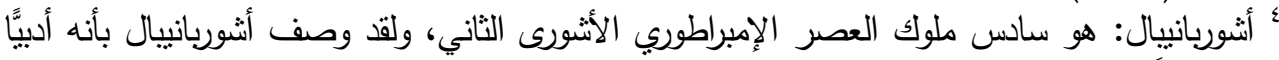

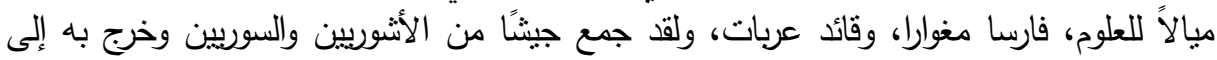

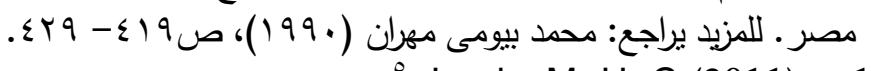

Lewis. M. H. C (2011), p.111.

'Heidel. A (1971), p.60, Tablet VII, Line 38. Heidel. A (1971), p.122 lines 29, 30.

"سن: هو إله القمر يسمى في اللغة السومرية "نانّا"، وفي الأكادية "سن"، وهو ابن الإلهين "إينليل ونينليل"،

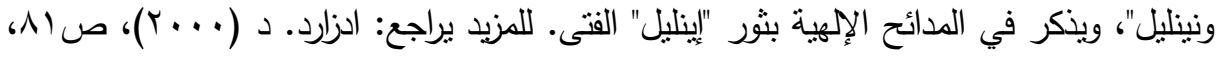

${ }^{9}$ Ferris J. S (1969), p.386. 
"سين" حيث أن السماوات لا نُعرف خفاياها فكذلك الإله "سين"، ومن المعروف أن البحر

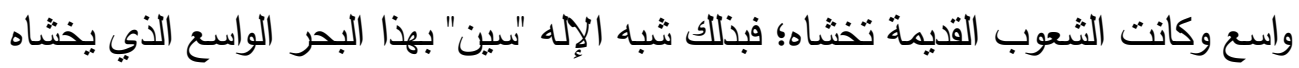

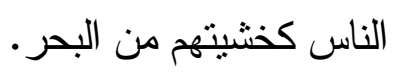

وفي الأسطورة السومرية تفسير لبدء نتظيم الكون؛ فجاء أن أصل الأجرام النيرة

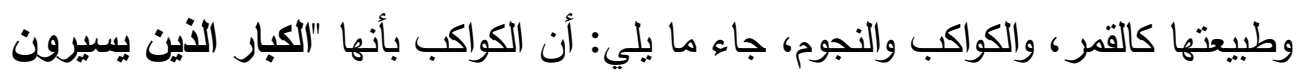

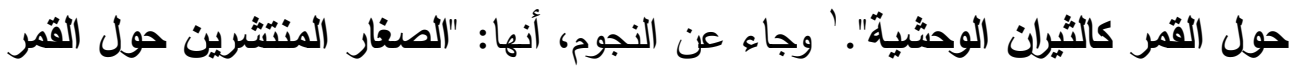

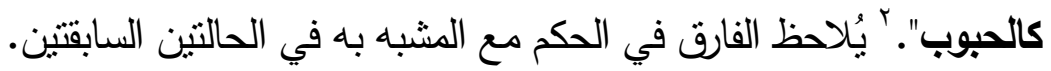

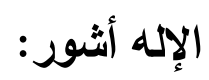

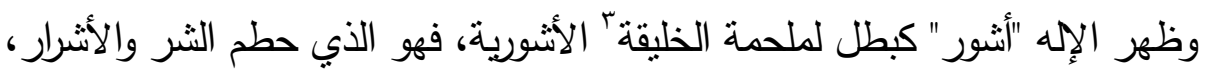

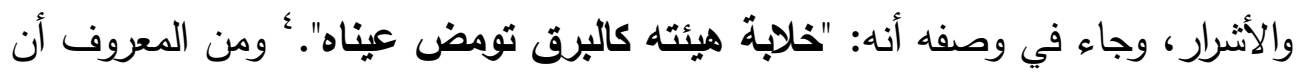

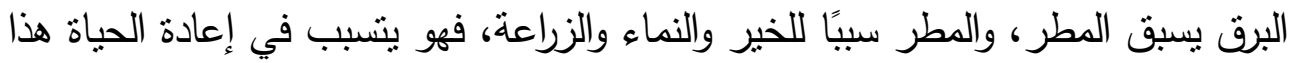
من ناحية. (يمش (الصيف):

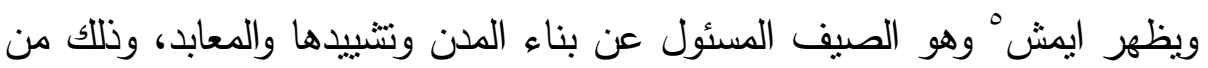

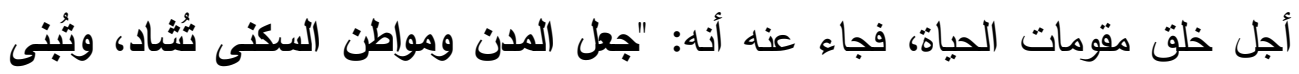
البيوت في البلاد، وترتفع المعابد كالجبال". ولعل ارتفاع المعابد كالجبال يمكن تفسيره

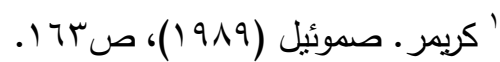

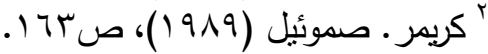

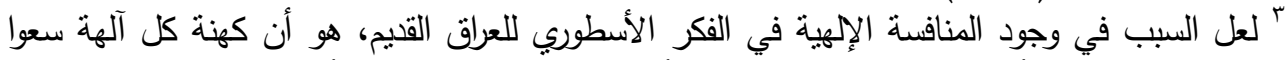

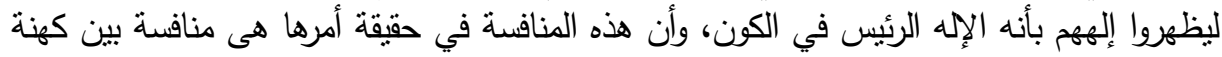

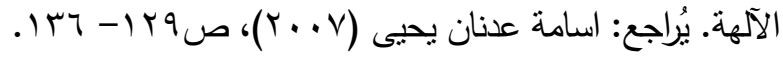

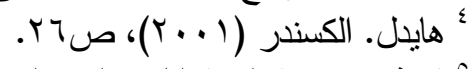

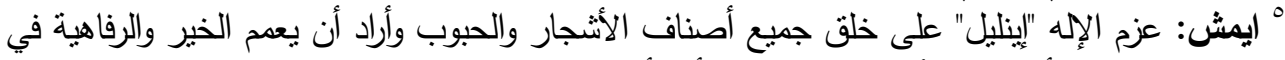

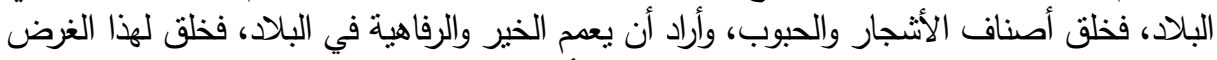

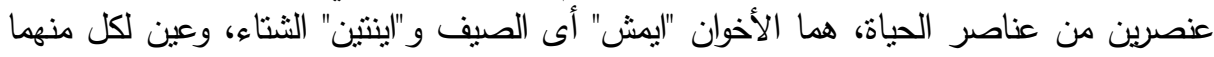

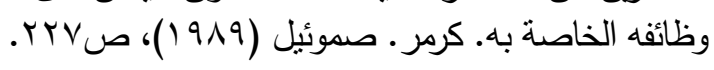


لسبيين، الأول: أن ارتفاع المعابد كالجبال ربما كان مُرتبطًا بعادة العراقي القديم إقامة معابده

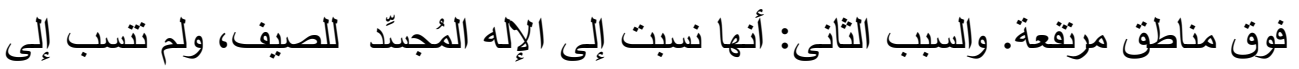

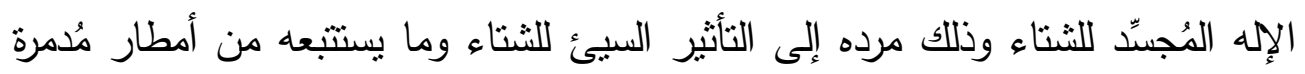
على معابد العراقي القيبم. الإله نينورتا:

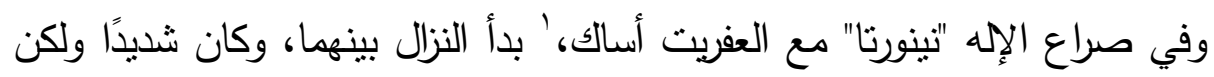

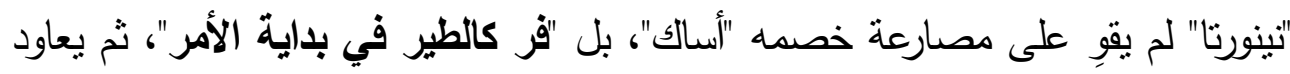

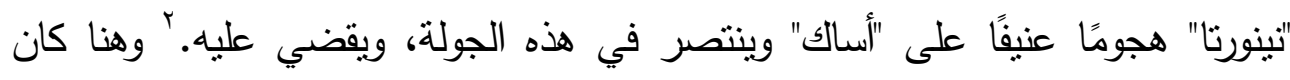

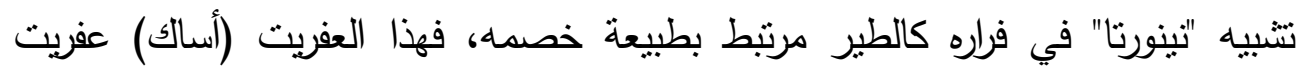

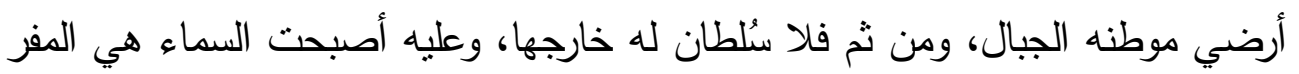

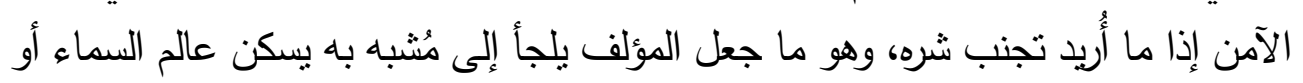

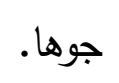

\section{الأم خويور (مرتبطة بالعالم السفلى)}

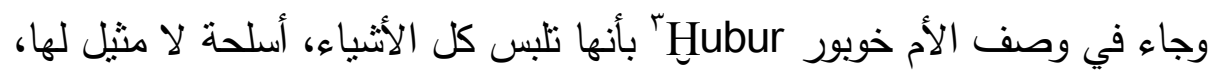

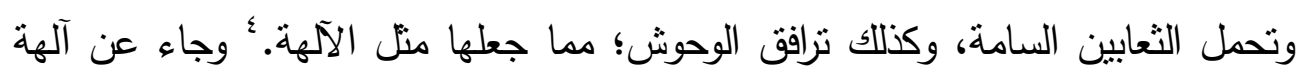

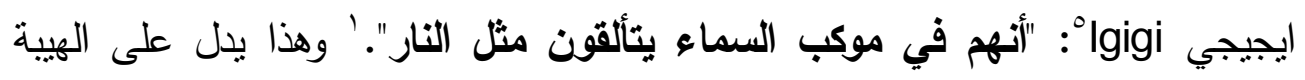

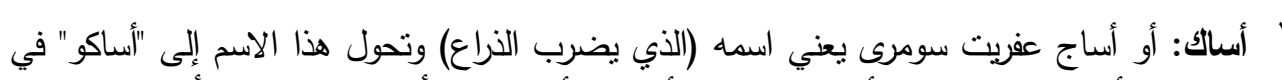

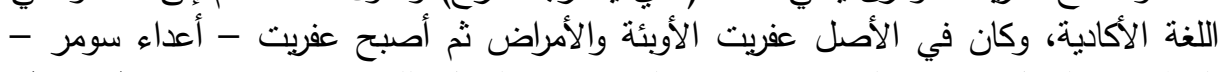

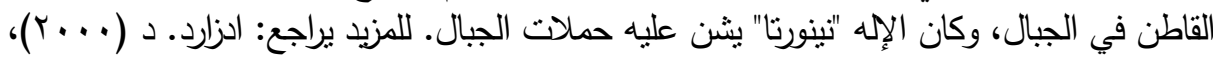
ص (10)

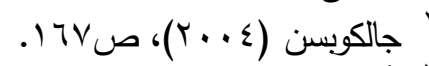

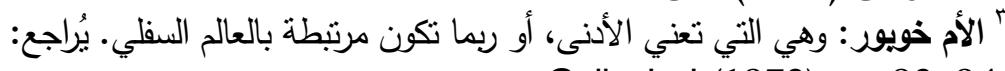
Gelb. I. J (1973), pp.93, 94.

'Speiser. E. A (1969), p.62; Jacobsen. T (1943), pp. 170. " آلهة الايجيجي: آلهة كانت في السماء ونزلت إلى الأرض ويرأسهم الإله إينليل، دائيًا ما ينم ذكرهم مع

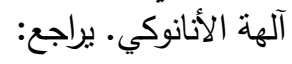
Jordan. M., (2004), p.134. 
والسمو بنتبيه بعض الآلهة بالنار.` ومن المعروف أن آلهة ايجيجي آلهة سماوية، وأن السماء موطن النجوم، والنجوم لها طبيعة نارية. الطائر أنزو:

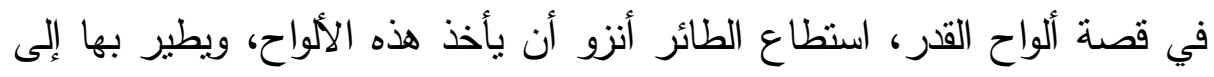

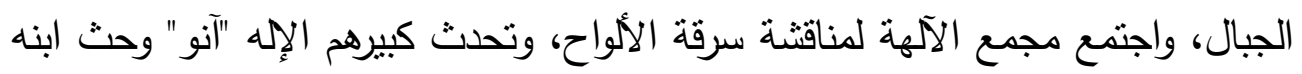

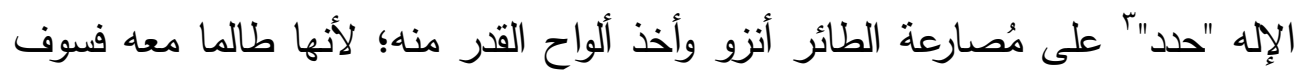

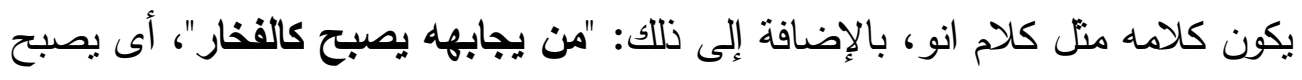

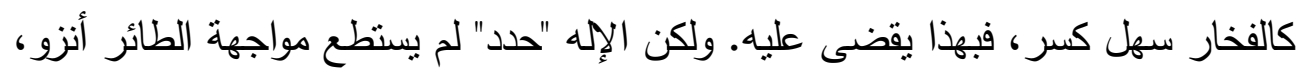

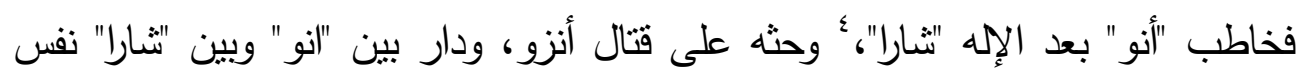

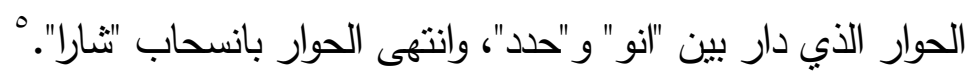

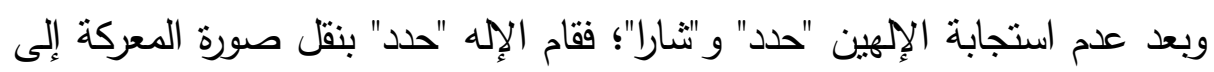

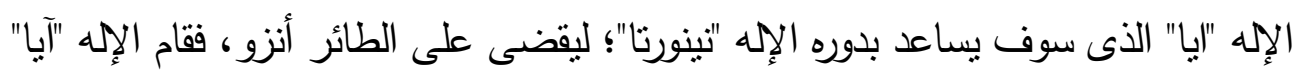

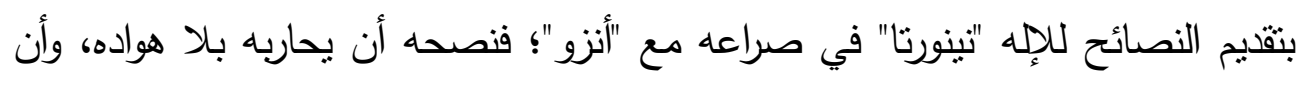

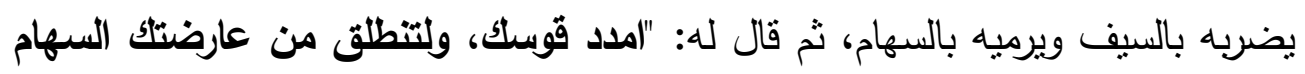

\section{'Kramer. S. N (1969), p.59.}

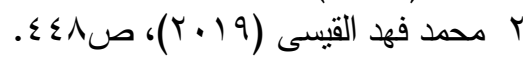

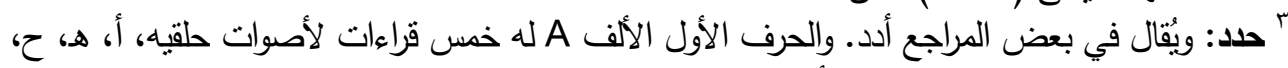

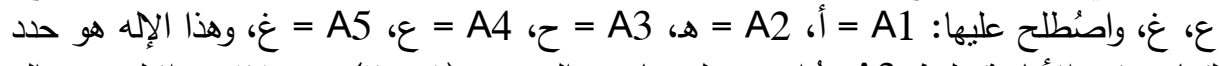

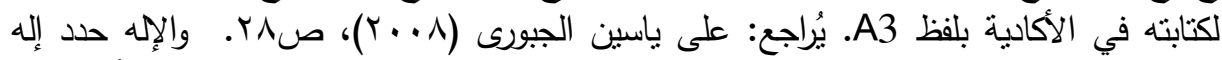

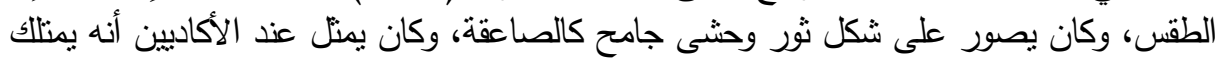

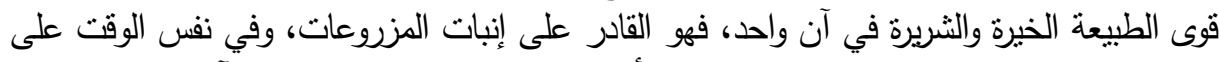

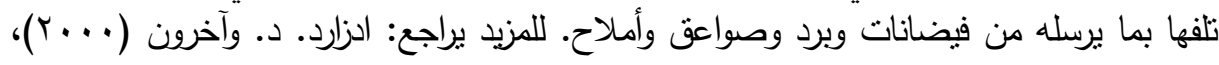

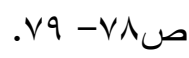

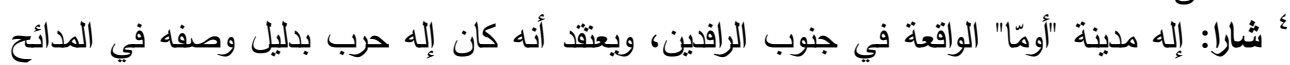

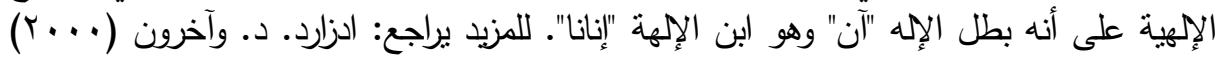

- Scurlock. J. A (2012), p.370. 
مثل البرق".' ومن المعروف أن البرق من الأسلحة التي نتتخدم للقضاء على الأعداء،

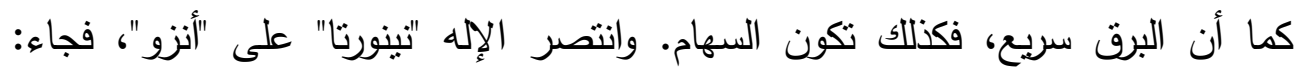

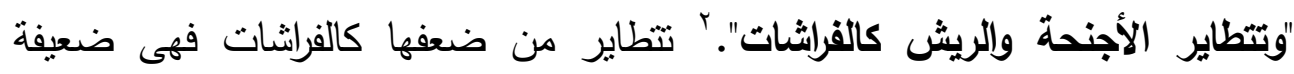

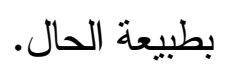

\section{التثبيه في الأساطير المرتبطة بخلق البشر:}

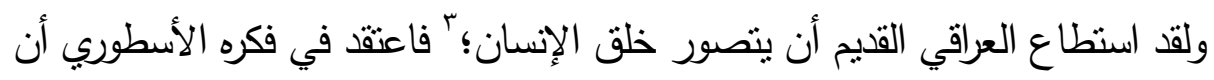

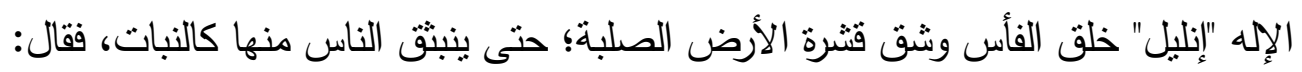

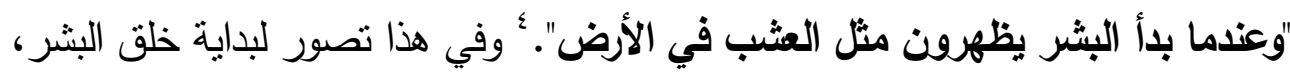

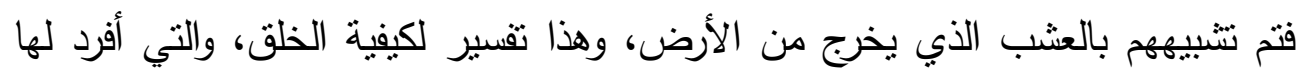
العراقيون القماء أساطير في بداية خلق الإنسان. التشبيه في أسطورة جلجامش:

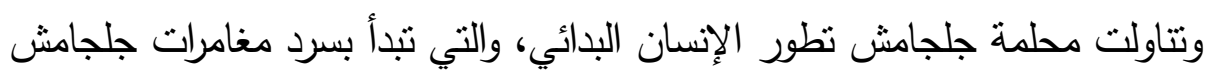

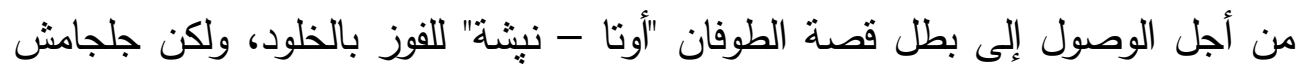

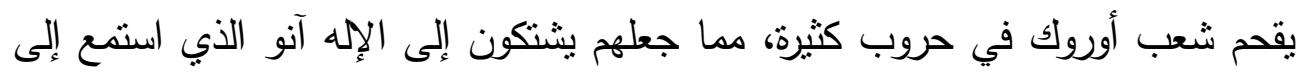

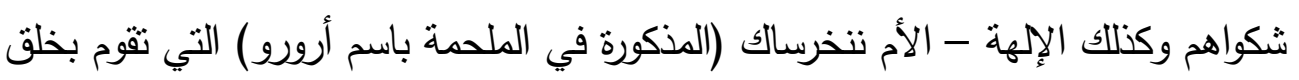

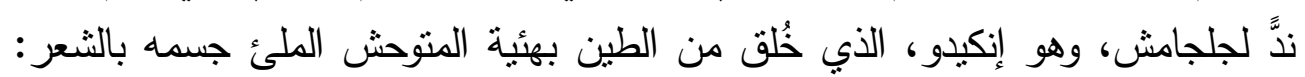

'Annus. A (2002), p. 104.

'Annus. A (2002), p. 104.

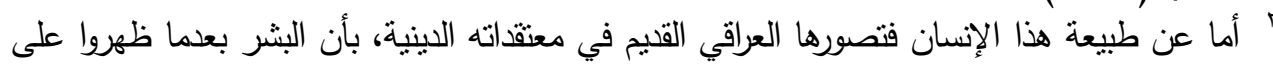

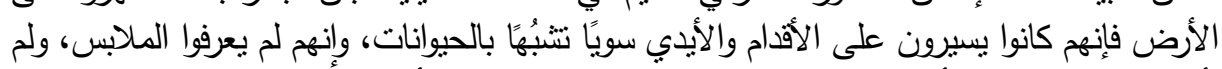

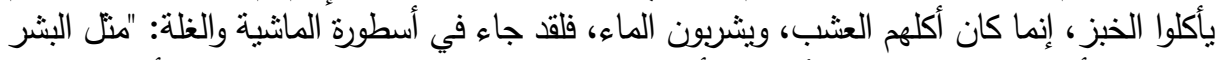

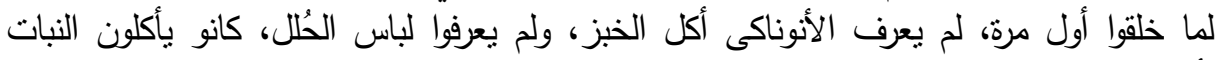

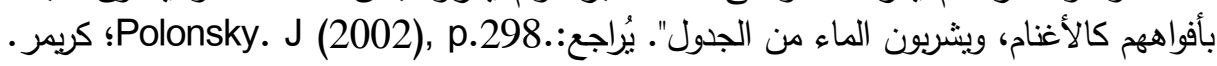

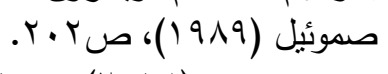


'طويل شعر الرأس مثل شعر المرأة، له خصل مثل الإلهة نيسابا' (إلهة الحبوب) سنابل

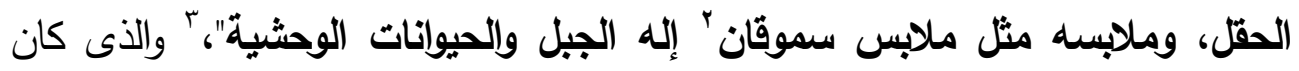

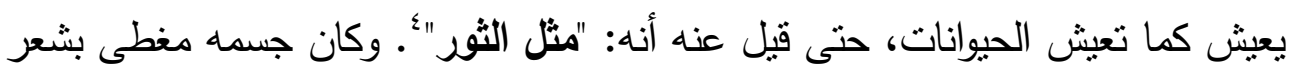

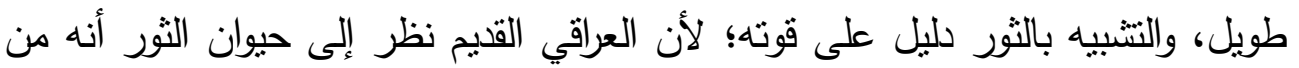

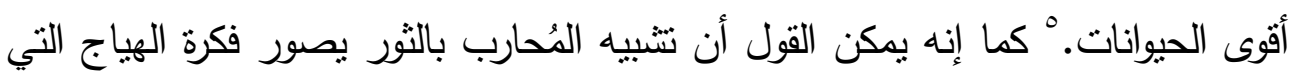
تميز الثور عن غيره من الحيوانات، كما إنه مرتبط بمفهوم الطوفان بحكم كونه مظهر من النيات التهات مظاهر الهياج الهيدرولوجية.

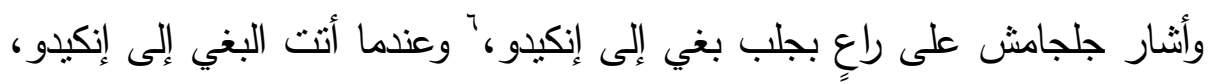

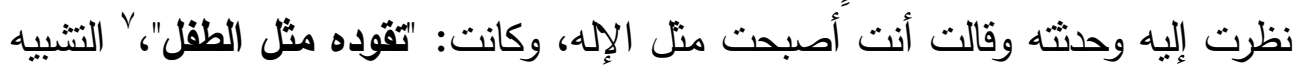
هنا لليل على طاعة إنكيدو لها كما يطيع الطفل من يقوده في الغالب. وبعد ذلك خلعت ملابسها وجامعها إنكيدو من الخلف - كما يفعل الحيوانات -

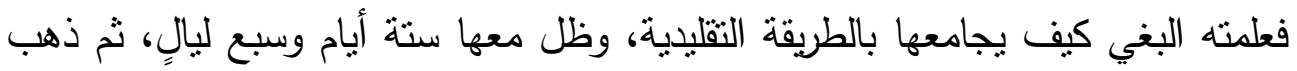

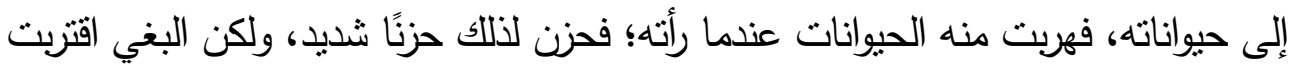

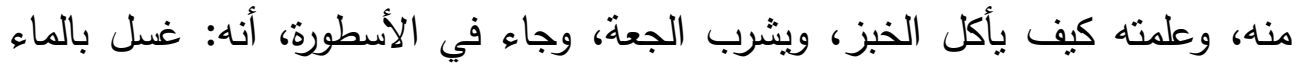

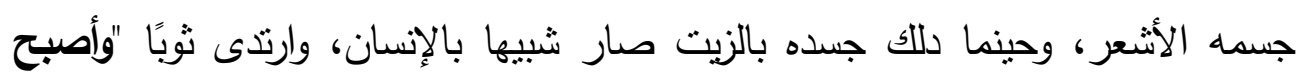
كالمحارب". التتبيه لاكتسابه الصفات البشرية، والقيام بحياته كمحارب.

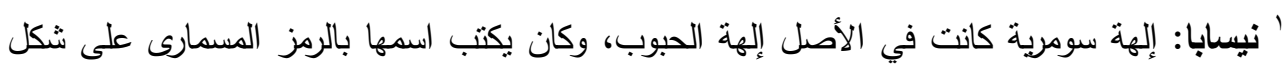

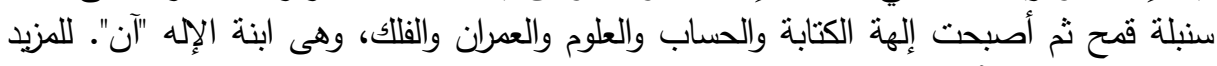

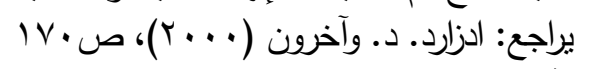

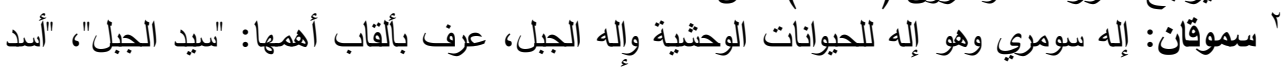

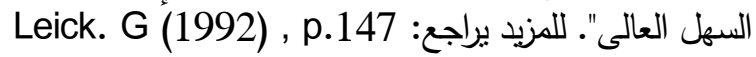

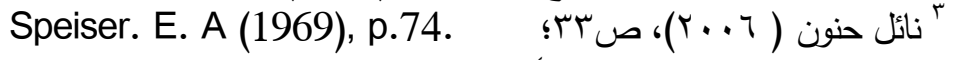
¿ George. A (2000), p.3.

Taheri. A (2013), p.16

'Speiser. E. A (1969), p.77.

George. A (2000), p.105.

${ }^{\wedge}$ George. A (2000), p.105. 
ثم يتحدث جلجامش لإنكيدو عما رآه في منامه بأنه ارتعت السماء، رجت

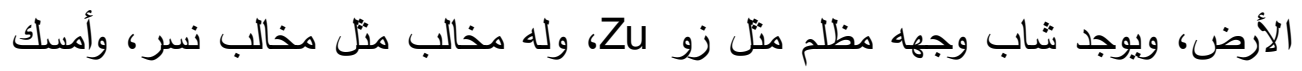

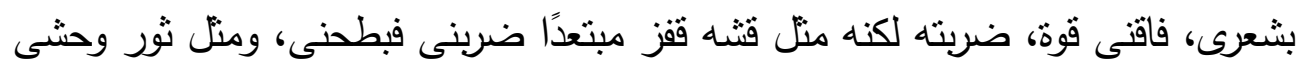

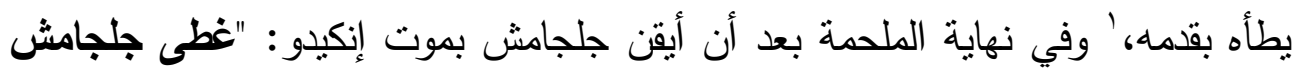

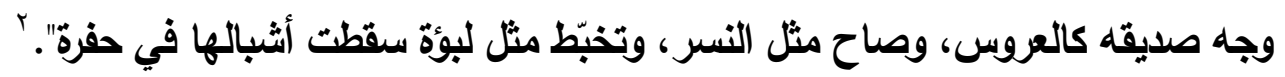

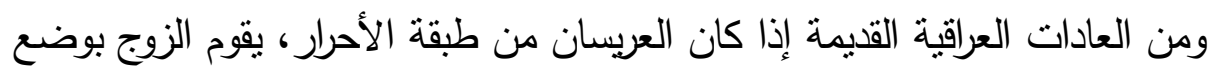

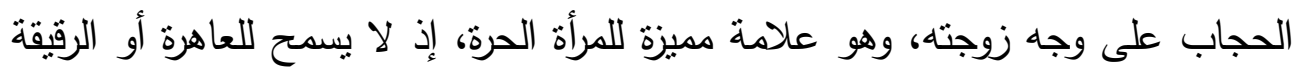

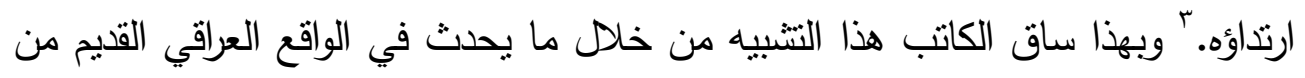
وضع الزوج غطاء على وجه زوجته. ويقول إنكيدو لجلجامش حين يسأله الأخير عن الأحوال في العالم السفلى، يبدأ

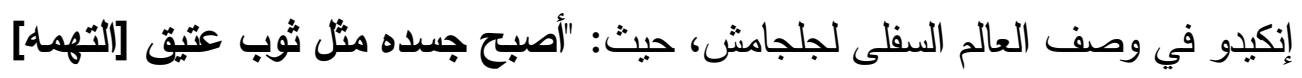

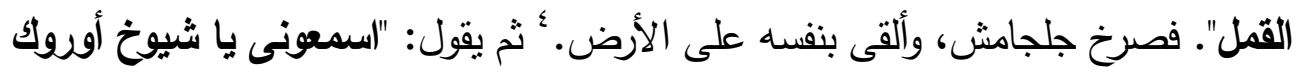
أوروك سأبكى إنكيدو صديقى مثل امرأة نادبة سأبكى بمرارة".

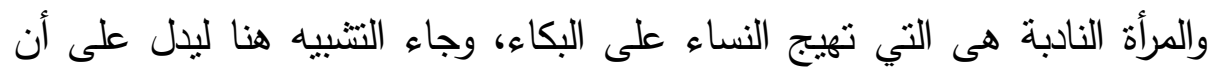
البكاء سيكون مستمرًا. ويسأل جلجامش عن رجل يموت، ويتزك أبناء، فيجييه إنكيدو، فمنها: "من خلّق

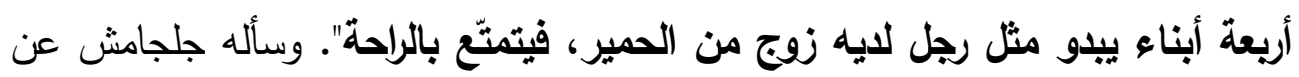

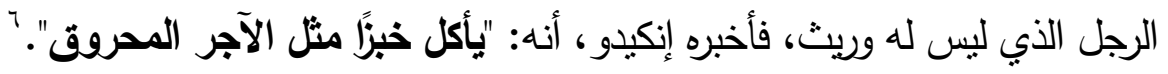

' Speiser. E. A (1969), p.87.

'De Villiers. G. G (2004), p.2- 28.

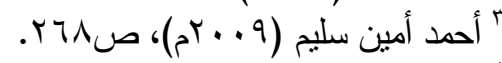

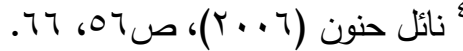

- George. A. (2000), p.64. 
يوجد في معتقد العراقي القديم أن كثرة الأولاد في الحياة الدنيا تعنى ضمان مكانة

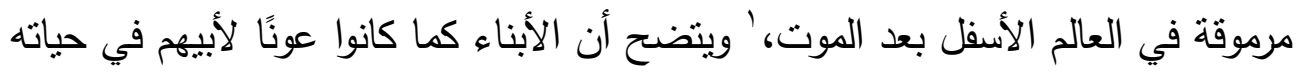
الدنبا، فإنهم سيكونون سبب سعادته وراحته في العالم الأخر .

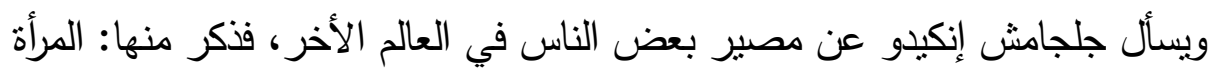

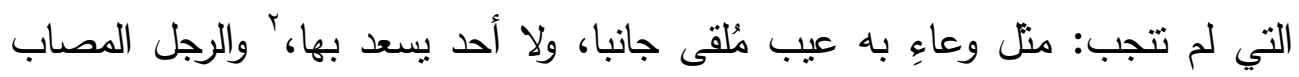

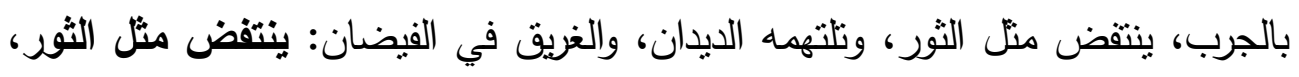
وتتلتهمه الايدان. التشبيه في ضوء أسطورة العقاب الإلهى للبشر البشر

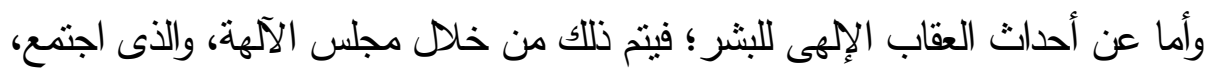

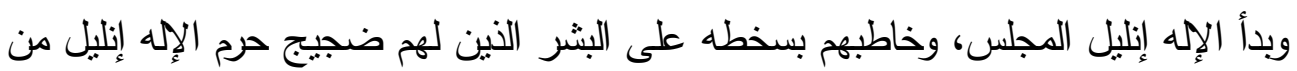

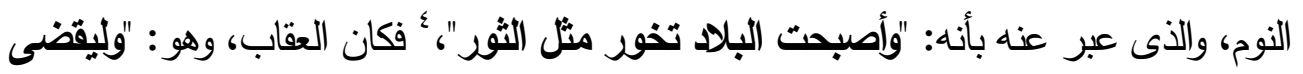

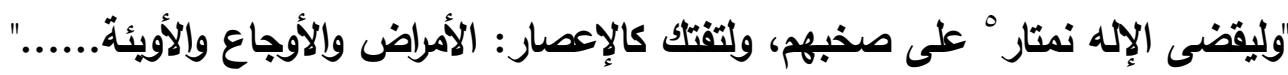

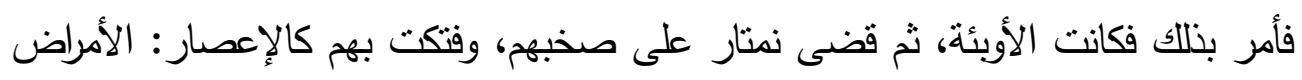

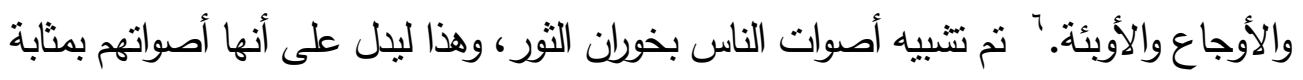

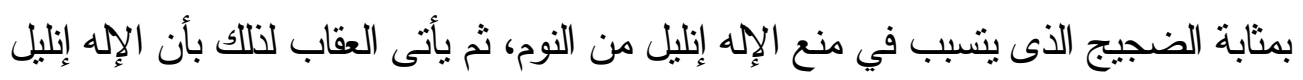

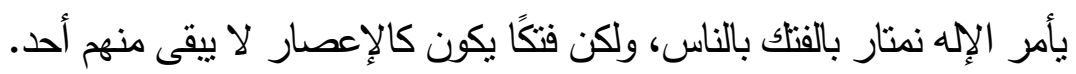

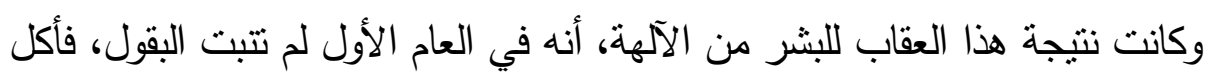

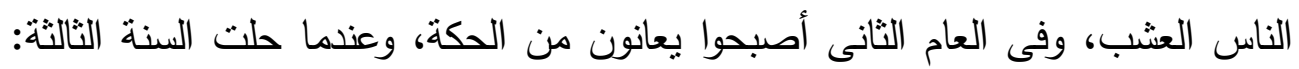

' Bayliss. M (1973), p.117.

'De Villiers. G. G (2004), p.2- 28.

'George. A (2000), p.188.

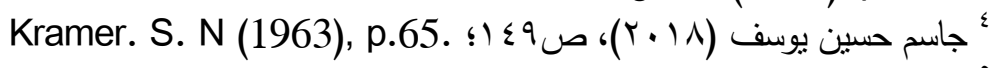

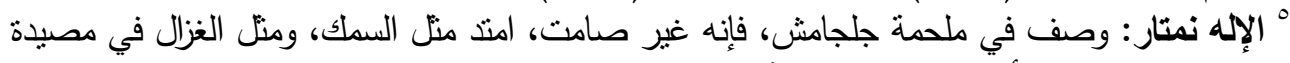

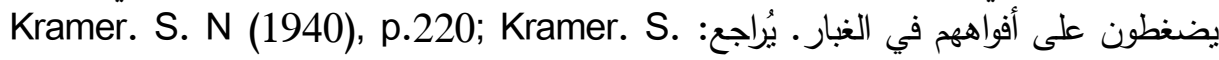

N., (1969), p.51 lines 73- 75.

Kramer. S. N (1940), p.220. 
تتغيرت ملامحهم بفعل الجوع، وغطت وجوههم غثاوة كالتبات المصفر، وكانوا أحياء ولكن على حافة الموت". ' وأُرِيدَ بهذا التتبيه التعبير عن نهايتهم، فالنبات في أواخر مراحله من النمو يصفر ثم يزيله الفلاح من الأرض. التشبيه في ضوء أساطير تلمير المدن: وفى تدمير مدينة أكد، كان قرار الآلهة العظام أمثال سين وإنكي واينانا ونينورتا

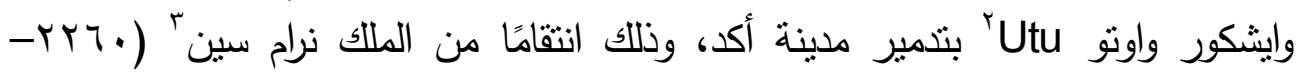

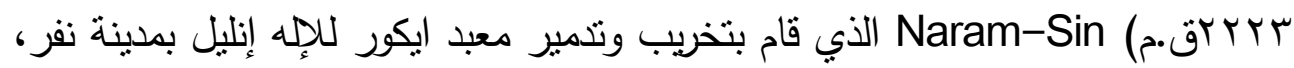

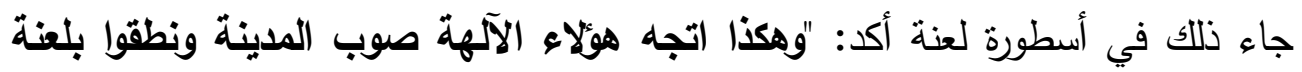

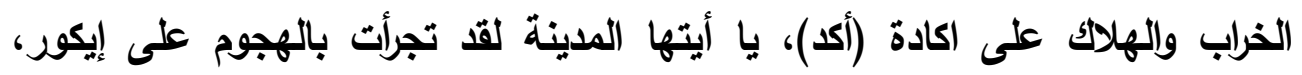

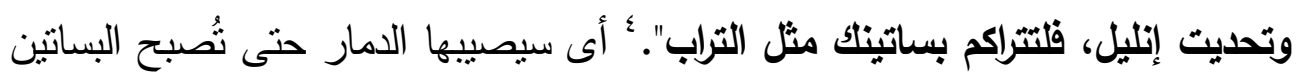

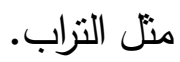

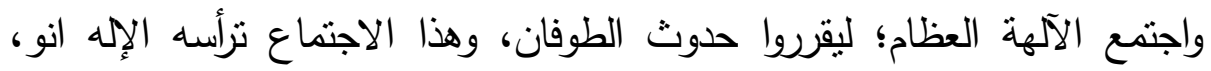

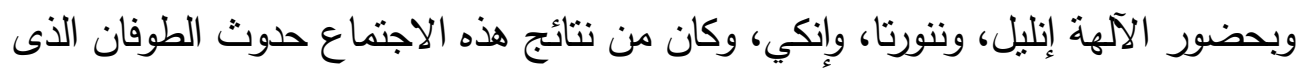

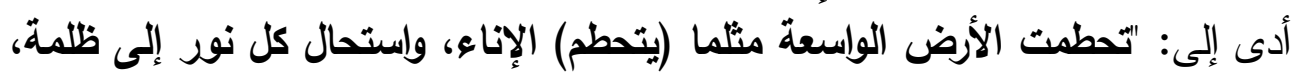

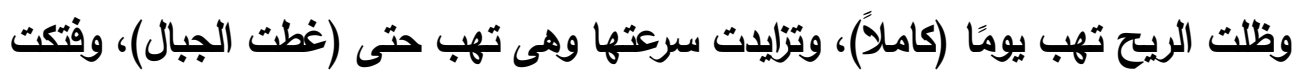
بالناس مثل الحرب الضروس".

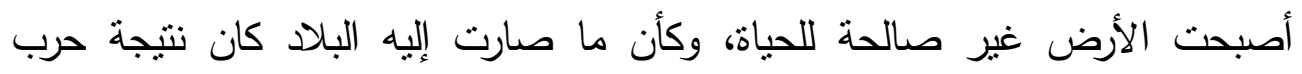
ضروس فتكت بكل الناس.

' Kramer. S. N (1940), pp.220, 221.

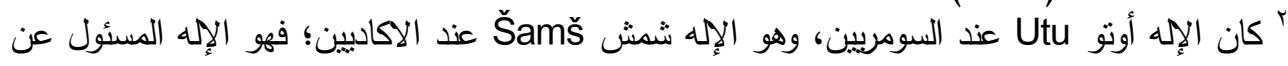

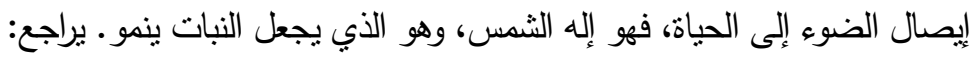

Black. J and Green. A (2004), p.182-184.

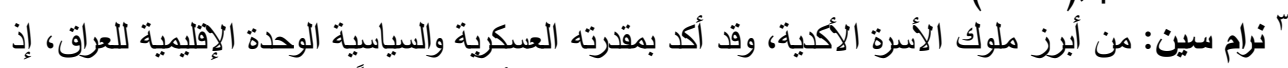

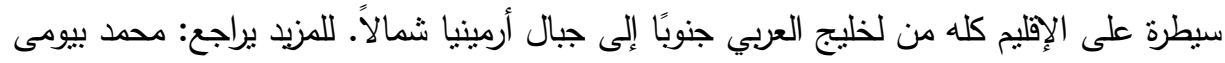

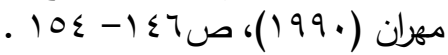

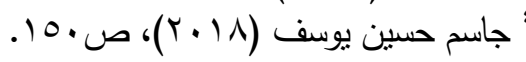

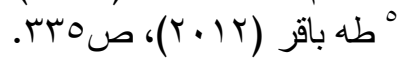


وتم تشبيه الآلهة أحيانًا بالطوفان، كماء جاء عن إنليل بأنه: "الطوفان العارم الأي لا

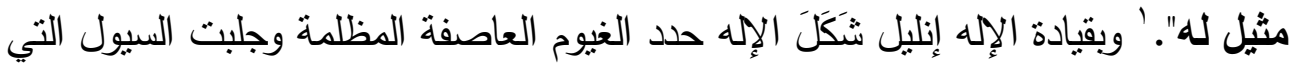

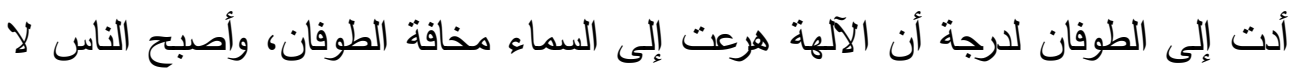

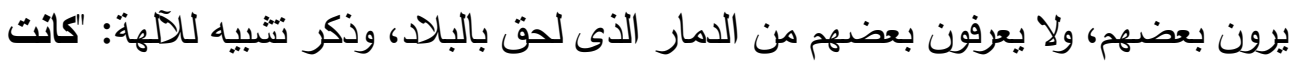

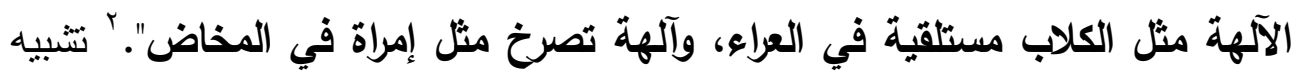

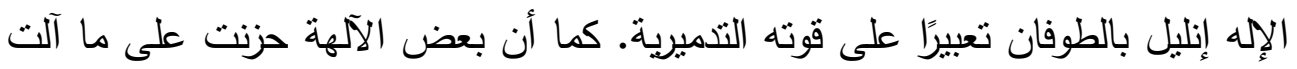

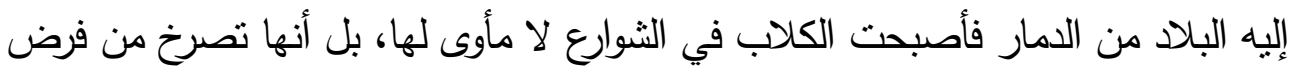
حزنها منل إمراة في مخاض الولادة.

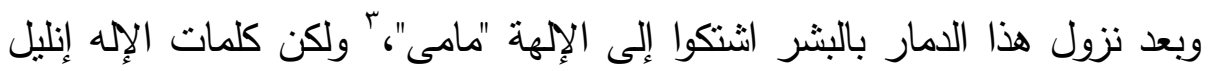

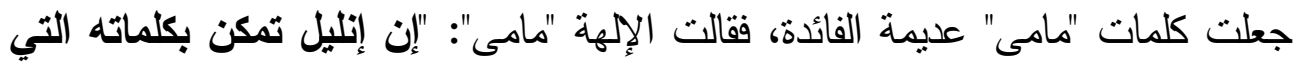

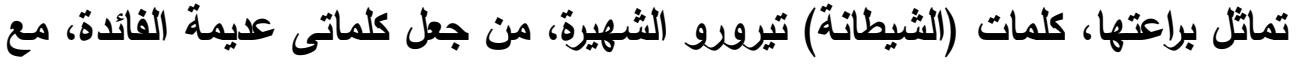

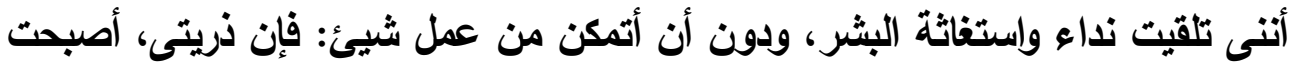

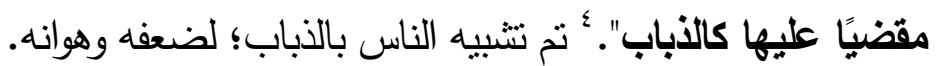

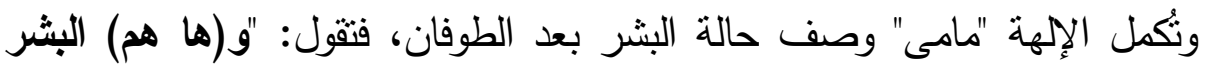

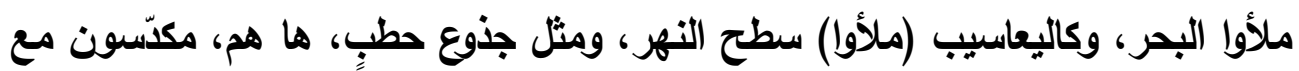

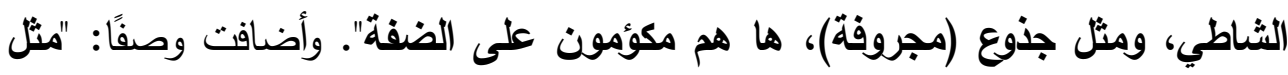
غنم حول حوض الإرواء، يبست شفاههم من القلق، وهم يترنّحون من شدّدة الجوع".

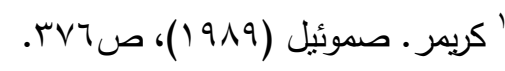

Garrison. J. A (2011), p.83, 84

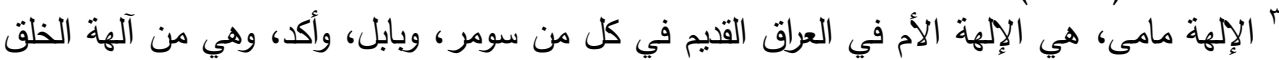

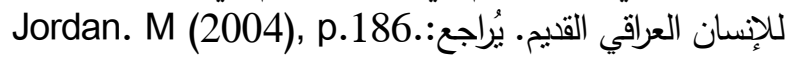

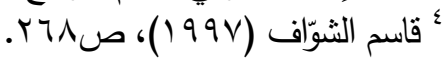

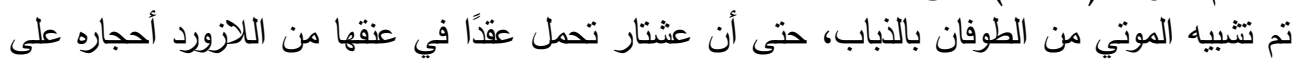

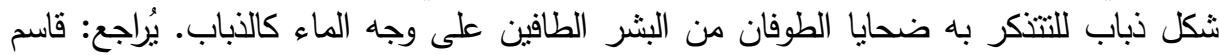

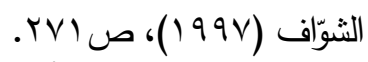

- Dalley.S (1984), p.33. 
وجاء في قصة جلجامش وصف الطوفان الذي دمر البشرية إن الإلهة عشتار:

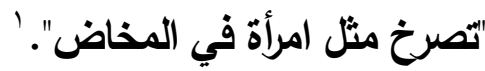

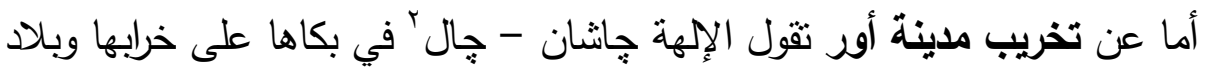

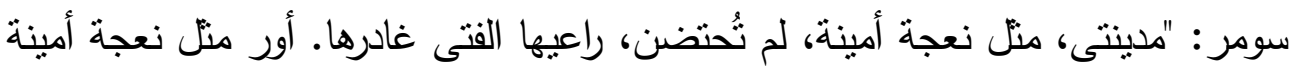

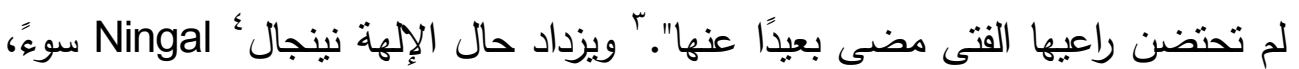

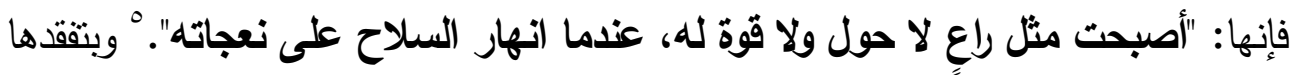

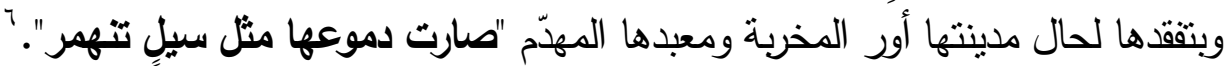

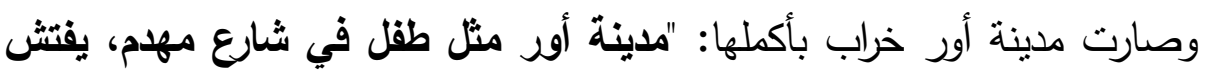

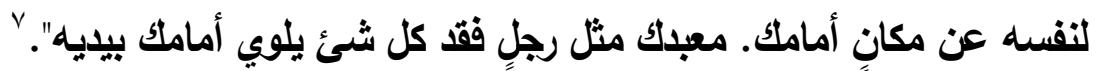

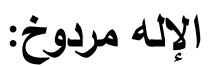

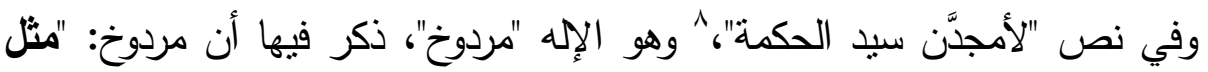

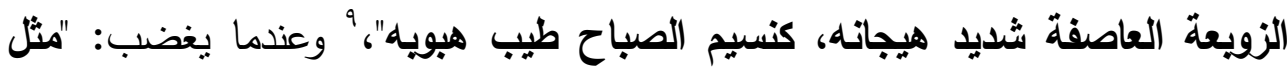

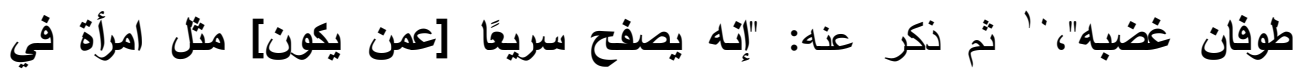

Harris. R (1991), p.264.

' جاشان - جال: إحدى إلهات مدينة أور، التى بكت على خراب مدينة أور . للمزيد براجع:

Black. J and Green. A (2004), p.135.

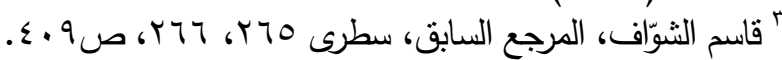
" الإلهة نينجال: هئ الأم الملكة الكبرى، زوجها هو الإله نانا وابنها الإله اوتو، وكانت نسمى أم أور.

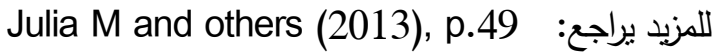

'Kramer. S. N (1940), p.53 line 305.

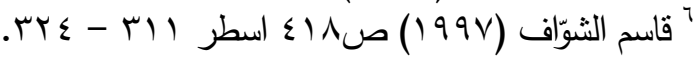

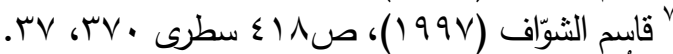

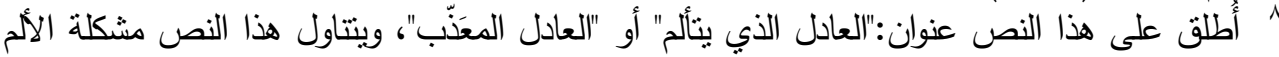

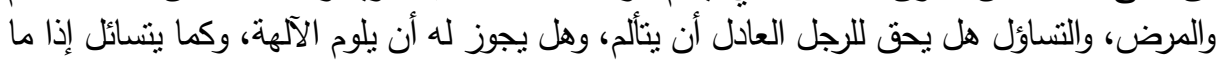

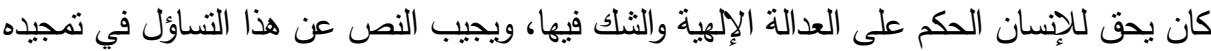

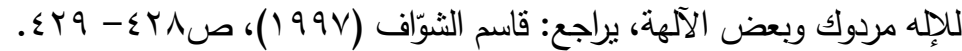

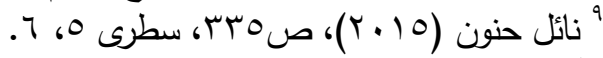
$-r \cdot-$ 
المخاض".' وأردف: "ليظهر هيجانه الأى مثل سمكة....." '. ونت تشيبيه الإله "مردوخ"

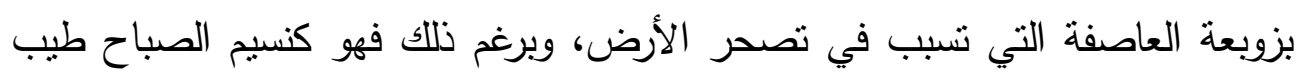

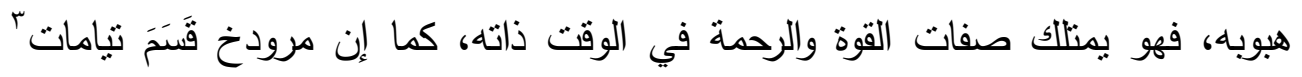
Tiamat السفلى.

ولقد شبه عصابة السبعة، وهم فرقة إيرّام التخريبية، وقال عنهم: "منعدموا الثفقة مثل

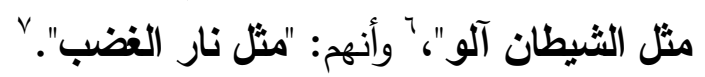

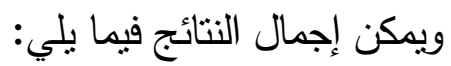

السماء والأرض: تم تشبيه الإله إنليل بالسماء في علوها، وعلم معرفة الناس بأسرارها

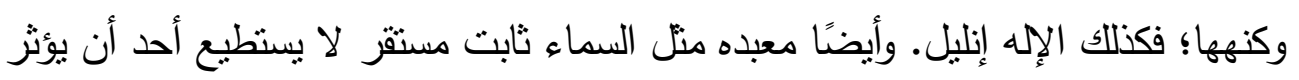

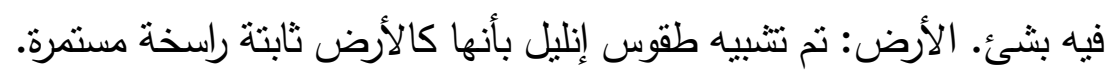

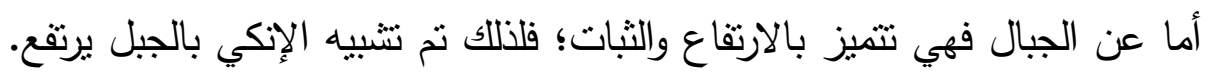

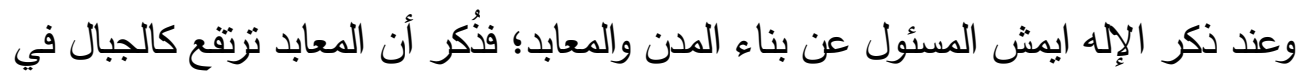
ثباتها وبقائها.

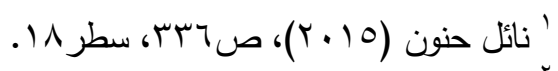

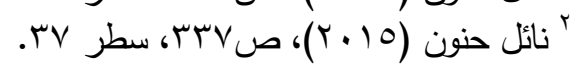

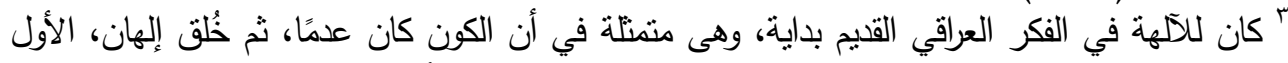

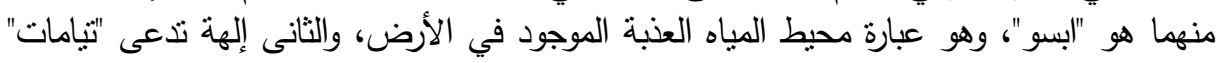

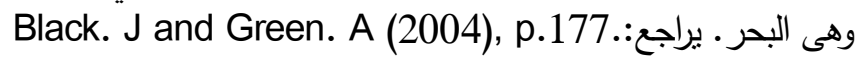
'Speiser. E. A (1969), p.67. إيرا: هو أحد الثيطان الذي يقوم بأعمال العنف والدمار . يراجع: Konstantopoulos. G. V (2015), p.162- 163.

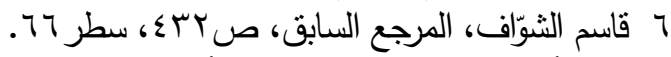

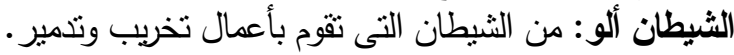
Konstantopoulos. G. V (2015), p.43.

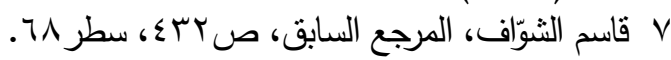


التتبيه بالفصيلة الحيوانية: ففي صراع كور مع الإله إنكي فكان كور كالأسد يضرب

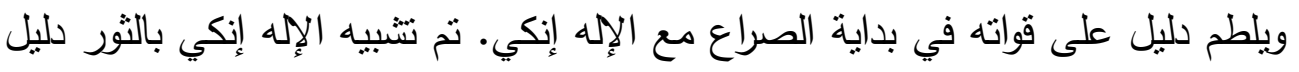

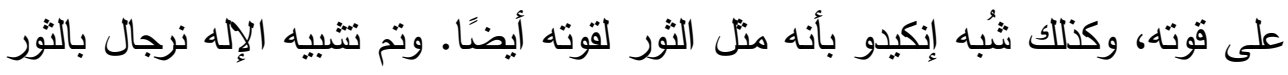

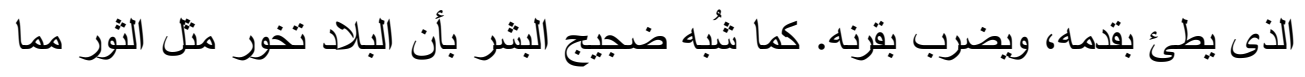

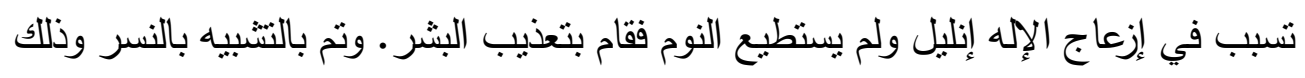

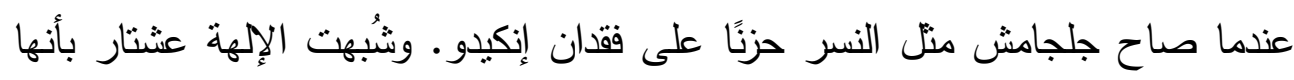

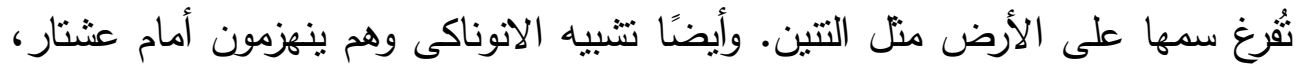

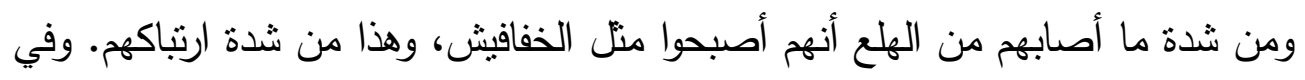

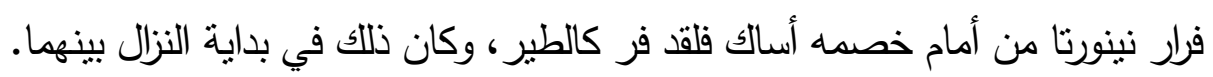

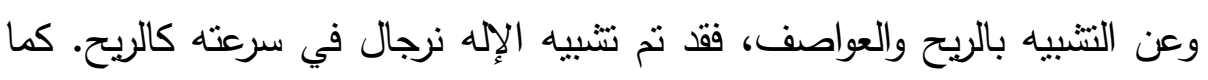

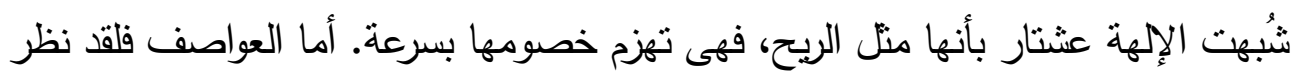

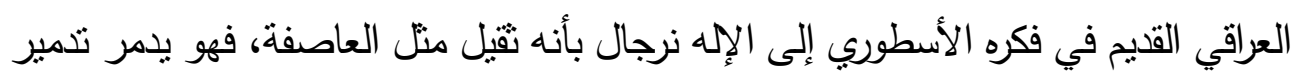

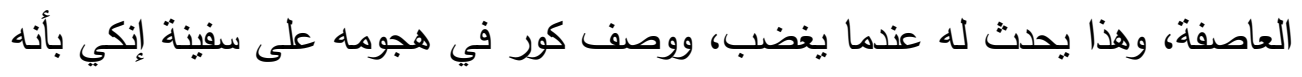
كالزوبعة. السحاب والمطر: أما السحاب فهي تنل على العطاء حيث تقيض بالماء الذي التي

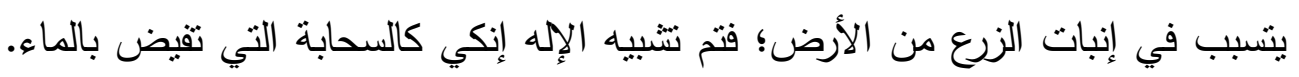

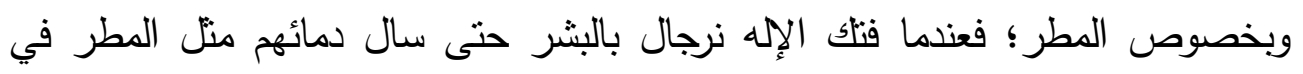
الأودية من كثرته، ويوضح ذلك مدى فتلك الإله نرجال بالبشرية.

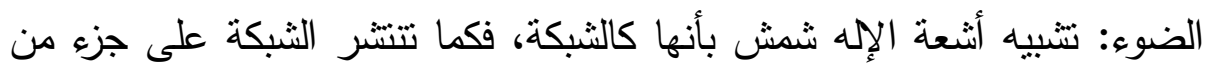

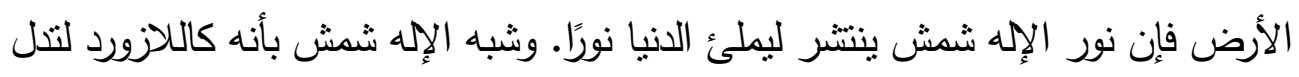

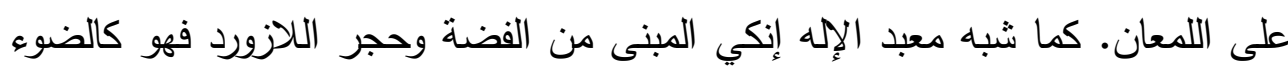

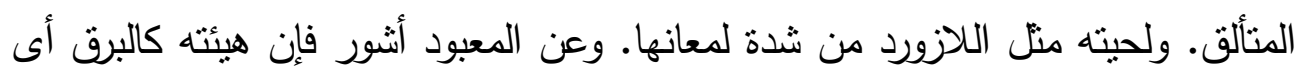

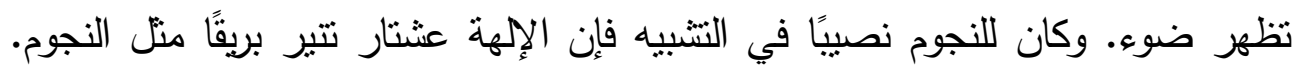

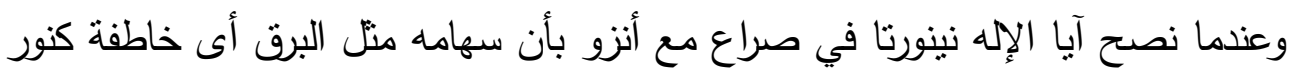


البرق السريع. ومن الأثنياء الدالة على الضوء النار، فلقد جاء عن آلهة ايجيجي أنهم في

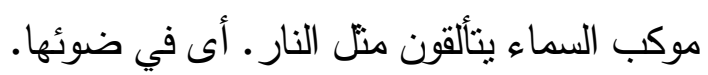

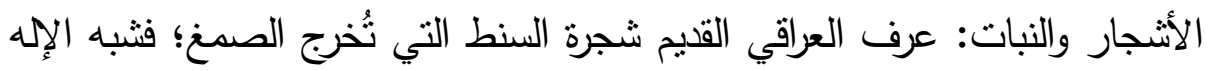

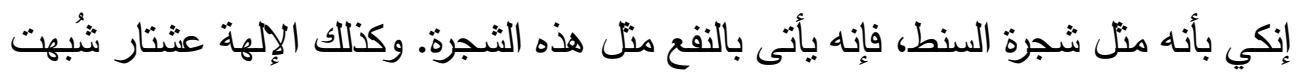

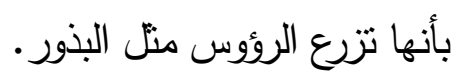

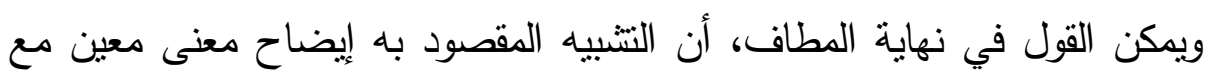

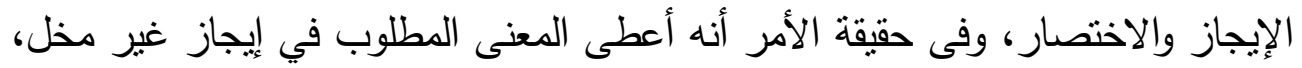

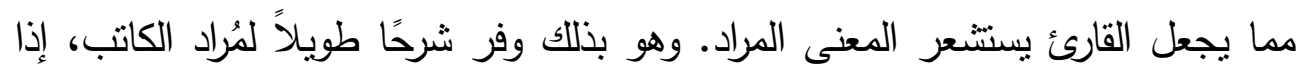

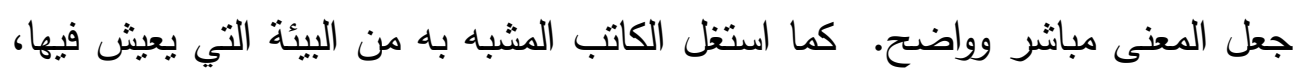
فبذللك جاء الكلام سهل الفهر.

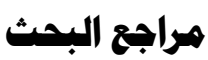

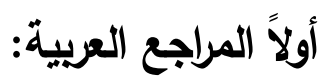

- أحمد أمين سليم، مصر والعراق ـ دراسة حضارية، الطبعة الثانية ( بيروت، دار

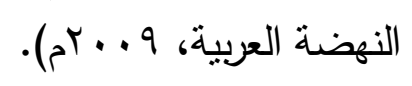

- ادزارد. د وآخرون، قاموس الآلهة والأساطير في بلاد الرافدين (السومرية والبابلية)

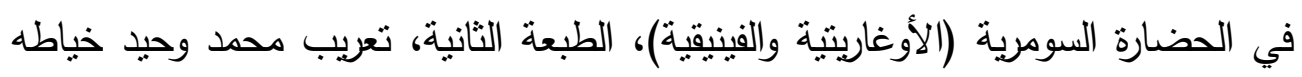

$$
\text { (لبنان: دار الثرق العربى، .... ب). }
$$

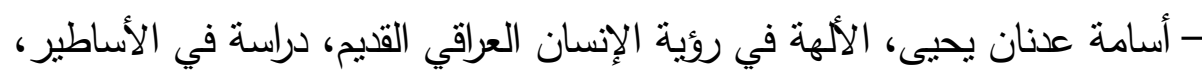

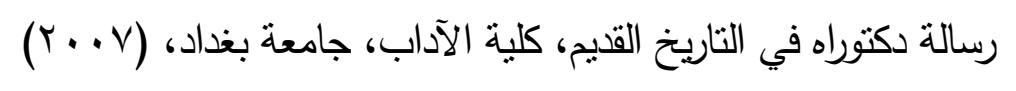

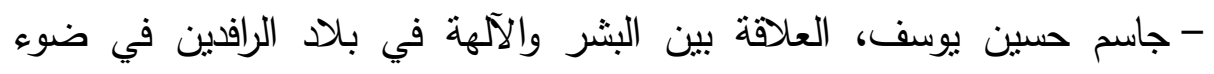

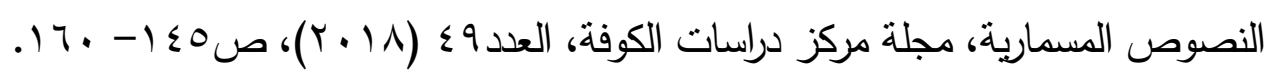

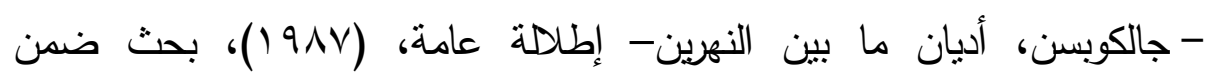

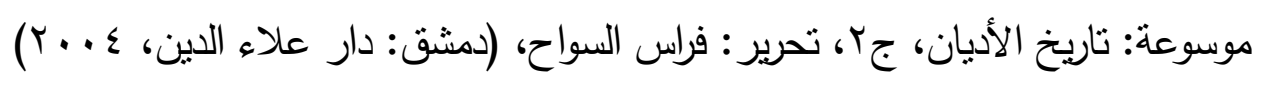

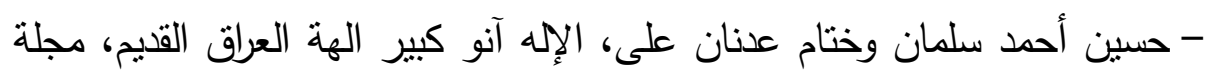

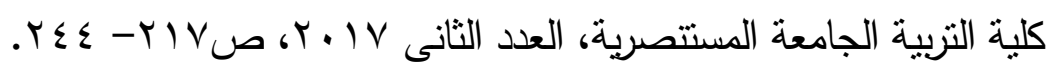


- طه باقر، مقدمة في تاريخ الحضارات القديمة، الطبعة الثانية (بغداد: دار الوراق

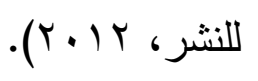

- عبدالعزيز عنتق، علم البيان، في البلاغة العربية، (بيروت: دار النهضة العربية،

- على ياسين الجبورى، قاموس اللغة الأكلية - العربية، (هيئة أبوظبى للتقافة

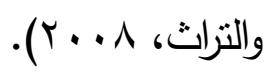

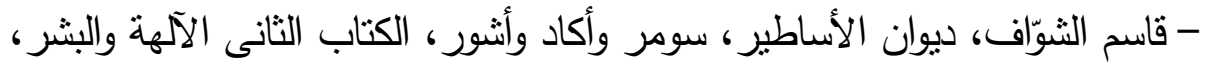
الطبعة الأولى، إثراف: أدونيس، دار الساقى، (لبنان: دار الساقى، لو لو (1).

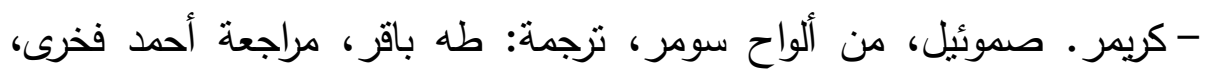

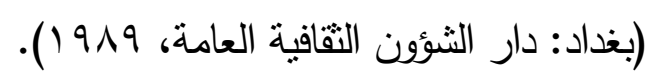
- مازن محد حسين، الأسطورة في بلاد الرافين دراسة في الفكر الأسطوري الملحمى الإنه

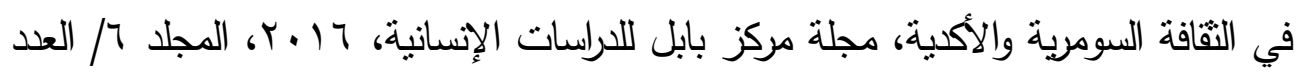

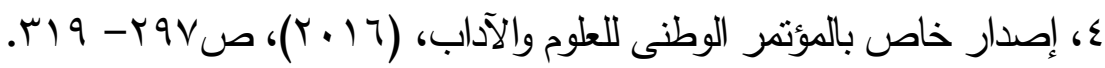

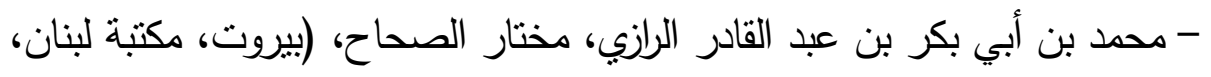

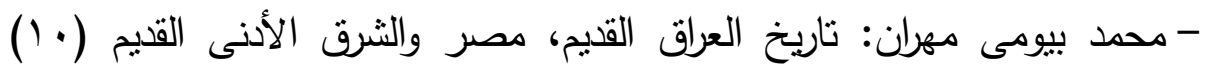
(الإسكندرية: دار المعرفة الجامعية، . 199 (19).

- محمد فهر القيسى، النار في أدب العراق القيميم دراسة تحليلية، مجلية كلية التربية

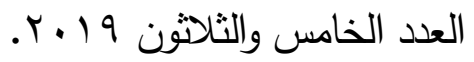

- نائل حنون، ملحمة جلجامش تزجمة النص المسمارى مع قصة موت جلجامش

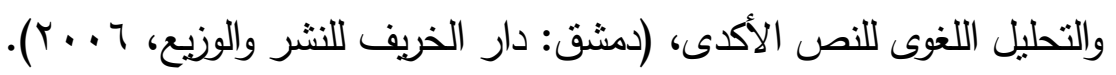

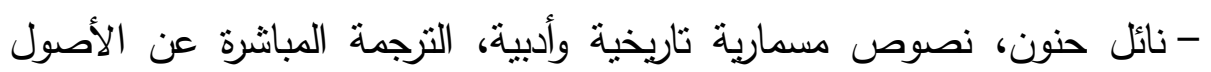

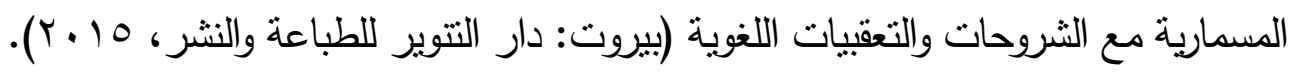


- هايدل. السكندر، الخليقة البابلية - قصة النشوء والتكوين عند قدماء العراقيين

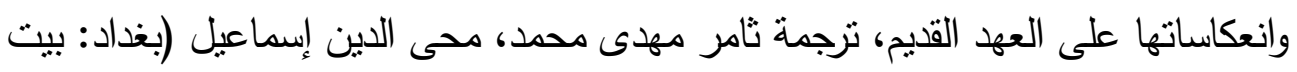

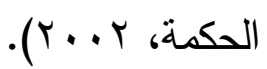

\section{ثانيًا: المراجع الأجنبية:}

- Annus. A., The God Ninurta in the Mythology and Royal Ideology of Ancient Mesopotamia , State Archives of Assyria Studies, Volume XIV, Helsinki (2002).

- Bayliss. M., The Cult of Dead Kin in Assyria and Babylonia, Iraq, vol $35,(1973)$, pp.115- 125.

- Black. J and others., A Concise Dictionary of Akkadian, Wiesbaden (2000).

- Black. J and Green. A., An Illustrated Dictionary Gods, Demons and Symbols of Ancient Mesopotamia, Illustrations by Rickards. T, The British Museum Press, London, (2004).

- Dalley.S., Myths from Mesopotamia, Creation, the Flood Gilgamesh and Others, Oxford (1984).

- De Villiers. G. G., Understanding Gilgamesh: His World and his Story, South Africa (2004).

- Espak. P., Ancient Near Eastern Gods Enki and EA: Diachronical Analysis of Texts and Images from the Earliest Sources to the Neo-Sumerian Period, Master's Thesis, Faculty of Theology, Tartu University, Tartu (2007). 
- ............ The God Enki in Sumerian Royal Ideology and Mythology, Dissertations Thedogiae Universitatis Tartuensis (19), Paris (2010).

- Ferris J. S., Prayer to the Moon God, in: Ancient Near Eastern Tests, Edited by Pritchard. J., New Jersey (1969), p.386387.

- Garrison. J. A., The Gilgamesh Epic and the Old Testament Prophetic Corpus, A Dissertation Submitted to the Doctor of Philosophy Committee of the Mid-America Baptist Theological Seminary, in the Old Testament Department, (2011).

- Gelb. I. J., Hurrians and Subariabs, Studies in Ancient Oriental Civilization, No.22, Chicago (1973).

- George. A., The Epic of Gilgamesh, The Babylonian Epic Poem and Other Texts in Akkadian and Sumerian, Penguin (2000).

- Harris. R., Inanna-Ishtar as Paradox and a Coincidence of Opposites, History of Religions, Vol. 30, No. 3 (Feb., 1991), pp. 261-278.

- Heidel. A., The Gilgamesh Epic and Old Testament Parallels, the University of Chicago, (1971).

- Heuzey. M. L., Dragons sacrés de Babylone et leur prototype chaldèen, Revue d'Assyriologie et d'Archéologie orientale, vol. VI, n" 3, (1906), pp.1- 10.

- Jacobsen. T., Primitive Democracy in Ancient Mesopotamia, Journal of Near Eastern Studies, Vol. 2, No. 3 (Jul., 1943), pp. 159-172. 
- ................ The líl of dEn-líl. DUMU-É-DUB-BA-A:

Studies in Honor of Åke W. Sjöberg (Behrens, H., D. M. Loding and M. T. Roth). (1989), pp.267-276.

- Jordan. M., Dictionary of Gods and Goddesses, the United States of America, (2004).

- Julia M and others., Goddesses in Context: On Divine Powers, Roles, Relationships and Gender in Mesopotamian Textual and Visual Sources, Zurich Open Repository and Archive, University of Zurich (2013).

- Konstantopoulos. G. V., They are Seven: Demons and Monsters in the Mesopotamian Textual and Artistic Tradition, (Near Eastern Studies) in the University of Michigan, (2015).

- Kotzé. Z., The Evil Eye of Sumerian Deities, Asian and African Studies, Volume 26, Number 1, (2017), pp.102 - 115.

- Kramer . S. N., Lamentation over the Destruction of Ur, Chicago (1940).

, The Sumerians, Their History, Culture, and Character, London, (1963).

- ..............., Sumerian Myths and Epic Tales, Ancient Near Eastern Tests, Edited by Pritchard. J., New Jersey (1969), pp.3759.

BM 100042: A Hymn to Su-Sin and an Adab of Nergal , DUMU-É-DUB-BA-A: Studies in Honor of Åke W. Sjöberg (Behrens, H., D. M. Loding and M. T. Roth). (1989). 
- Leick. G., A Dictionary of Ancient Near Eastern Mythology, (London and New York, 1992).

- Lewis. M. H. C., Warrior, Lover, Queen, Mother: The Goddess IŠTAR and her Relationship with Humanity, Master of Philosophy, Institute of Archaeology and Antiquity College of Arts and Law University of Birmingham October (2011).

- Muscarella. O. W., Bronze and iron. Ancient Near Eastern artifacts in the Metropolitan Museum of Art. New York: The Metropolitan Museum of Art, (1988).

- Polonsky. J., The Rise of the Sun God and the Determination of Destiny in Ancient Mesopotamia, Asian and Middle Eastern Studies, Presented to the Faculties of the University of Pennsylvania in Partial Fulfillment of the Requirements for the Degree of Doctor of Philosophy, (2002).

- Schwemer. M., The Storm-Gods of the Ancient Near East: Summary, Synthesis, Recent Studies, JANER 7.2 (2008), pp.121168.

- Scurlock. J. A., Marduk and His Enemies: City Rivalries in Southern Mesopotamia, Organization, Representation, and Symbols of Power in the Ancient Near East, Proceedings of the 54th Rencontre Assyriologique Internationaleat Würzburg 20-25 July 2008, edited by Wilhelm. G, Winona Lake, Indiana Eisenbrauns (2012), pp.369- 376.

- Smith. M. S., Athtart in Late Bronze Age Syrian Texts, Transformation of a Goddess: Ishtar - Astarte - Aphrodite, (Ed) 
Sugimoto, David T., Zurich Open Repository and Archive 39, (2014), pp.33- 85 .

- Speiser. E. A., Akkadian Myths and Epics, Ancient Near Eastern Tests, Edited by Pritchard. J., New Jersey (1969), pp.60119.

- Stephens. F. J., Sumero-Akkadian Hymns and Prayers, Ancient Near Eastern Tests, Edited by Pritchard. J., New Jersey (1969), pp. 383- 392.

- Taheri. A., The "Man-Bull" and the «Master of Animals» in Mesopotamia and in Iran, Intl. J. Humanities Vol. 20(1) (2013), pp.13- 28.

- Tallay. O., The Triumph of the Symbol: Pictorial Representation of Deities in Mesopotamia and the Biblical Image Ban, the Zurich Open Repository and Archive, University of Zurich (2005).

- Thompson. R. C., A Dictionary of Assyrian Botany, London, (1948).

- Van Buren. E. D., The Dragon in Ancient Mesopotamia, Orientalia,, Vol. 15 (1946), pp. 1-45.

- Wang. X., The Metamorphosis of Enlil in Early Mesopotamia, (2010). 